\title{
ICSO 2018
}

Chania, Greece

$9-12$ October, 2018

\section{Measuring, modeling and removing optical stray-light from Venps Super Spectral Camera images}

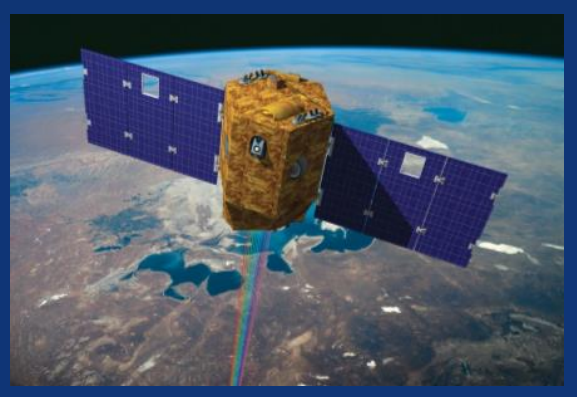

\section{Philippe Gamet}

Physics of Optical Measurements
Scientific Payloads \& Imagery

And also:

D. Laubier, S. Fourest (CNES)

T. Sprecher (ELOP)

E. Hillairet, J-P. Burochin (MAGELLIUM)

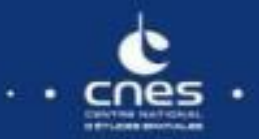




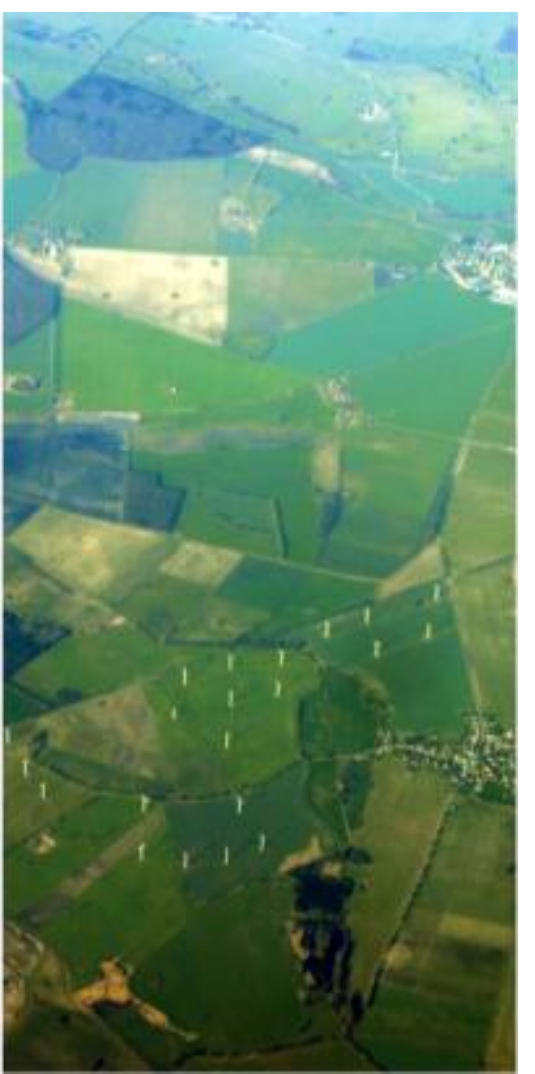

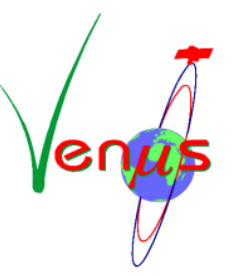

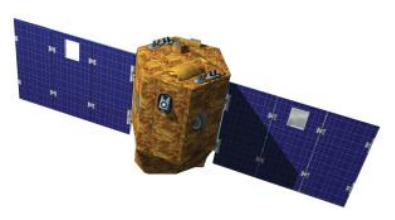

Ven $\mu$ s mission and camera

- Venus stray-light

- Ground measurement campaign

$\bullet$

- modeling of stray-light

- Stray-light correction

- $\quad$ Performance and results

- Performance and results

- Conclusions

\section{OUTLINE}
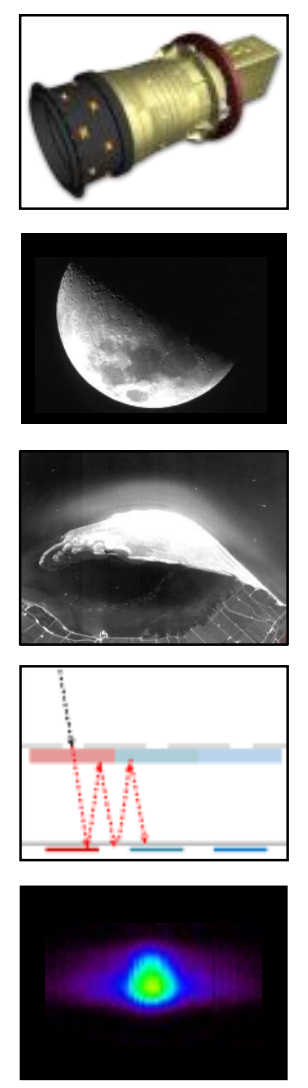

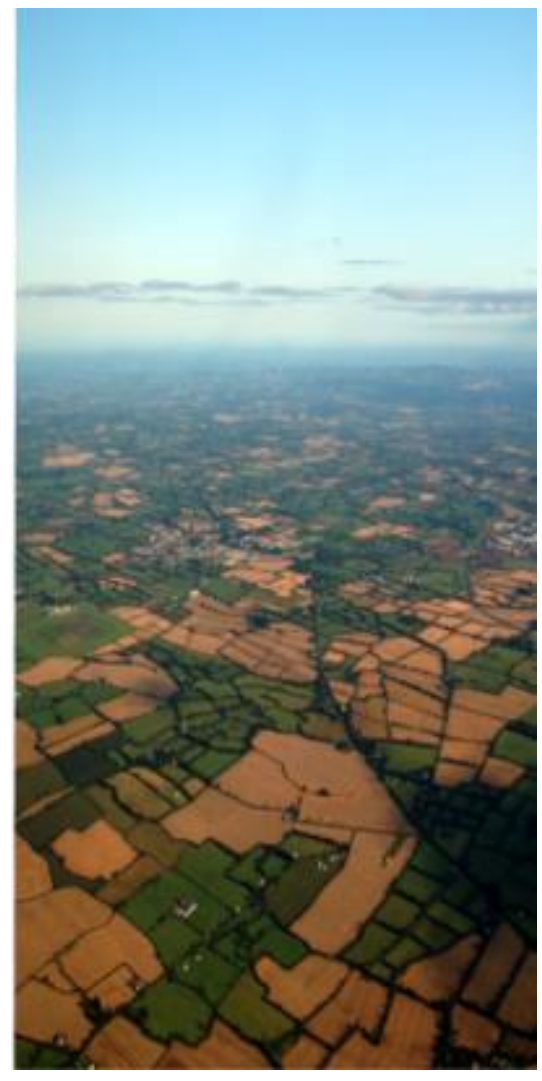




\section{OVERVIEW OF VEN $\mu S$}

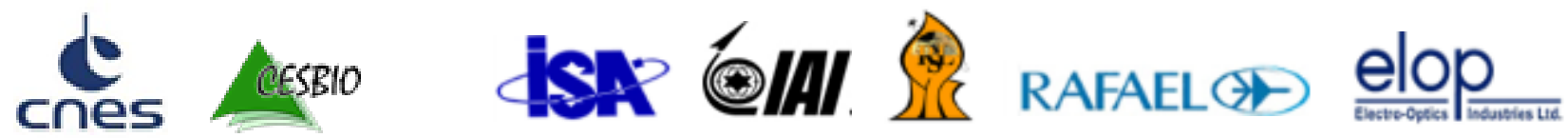

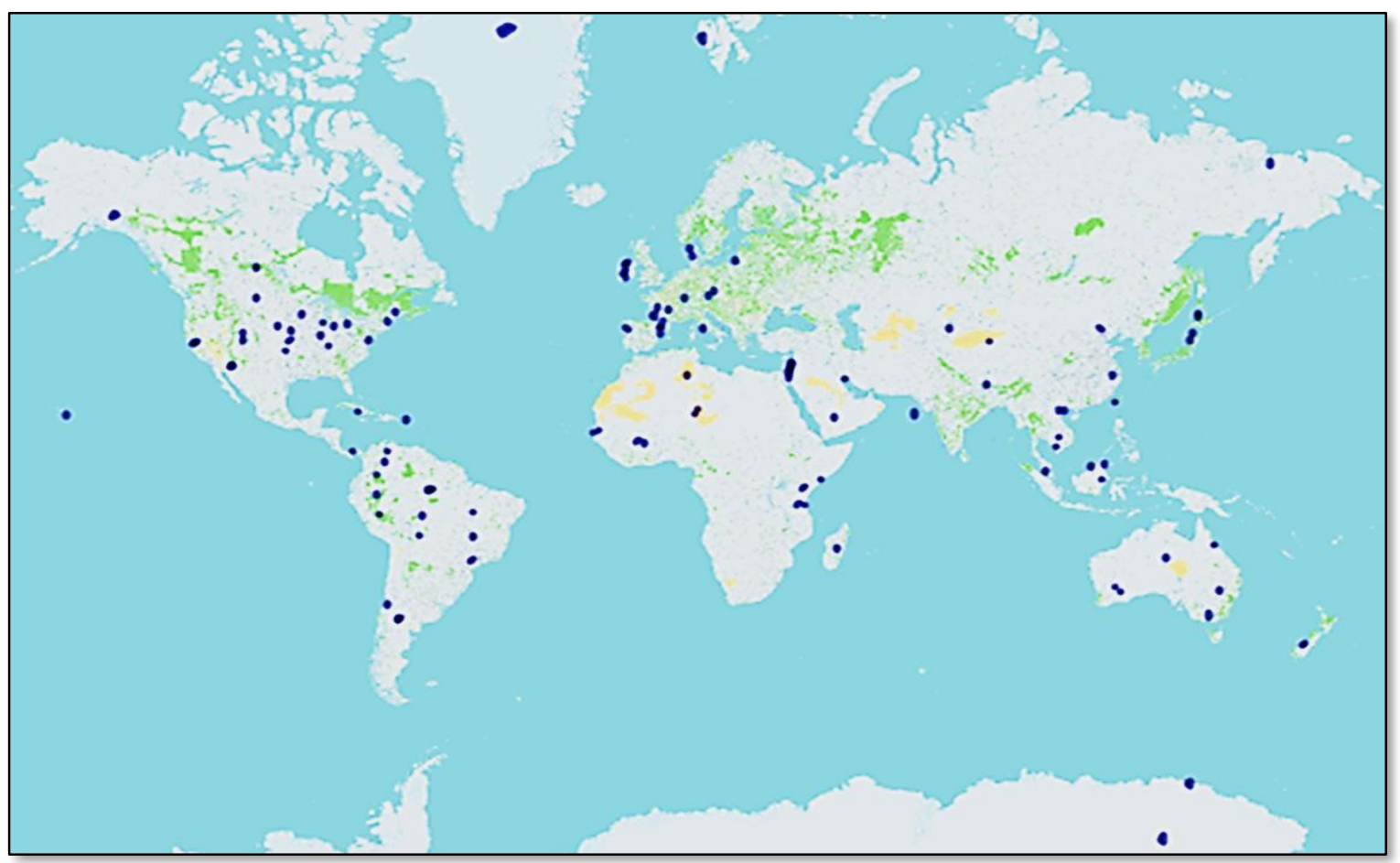

- $\mathrm{VEN} \mu \mathrm{S}=\ll$ Vegetation \& Environment monitoring on a New Micro-satellite »

- French - Israeli mission

- Study of vegetation, 2.5 years mission

$\leftarrow$ - 110 selected scientific sites

- 12 spectral bands in VNIR

- 2 days revisit, GSD $5.3 \mathrm{~m}$

- Tilting capability: $+/-30 \mathrm{deg}$

- Swath $27 \mathrm{~km}$

- Successfully launched Aug. 1, 2017

- Products on www.theia-land.fr 


\section{VEN $\mu S$ SUPER SPECTRAL CAMERA}

\section{VSSC derived from MSRS but with much more stringent requirements}

\section{Telescope}

- $1750 \mathrm{~mm}$ focal length F/7 Ritchey-Chrétien type, corrector optimized for telecentricity for spectral band uniformity in the FoV

- Light-weighted primary and secondary mirrors, composite material tube structure

- No refocus mechanism

- Tight specs to minimize stray-light (mirror roughness $5 \AA$, particle contamination $<300 \mathrm{ppm})$

\section{Focal plane}

- 4 tri-TDI detectors with 5200 pixels

- Equipped with 4 tri-band custom stripe filters with absorbing coatings between bands

- Highly complex filters (very steep response)

- In-field separation, with prism mirror to minimize separation
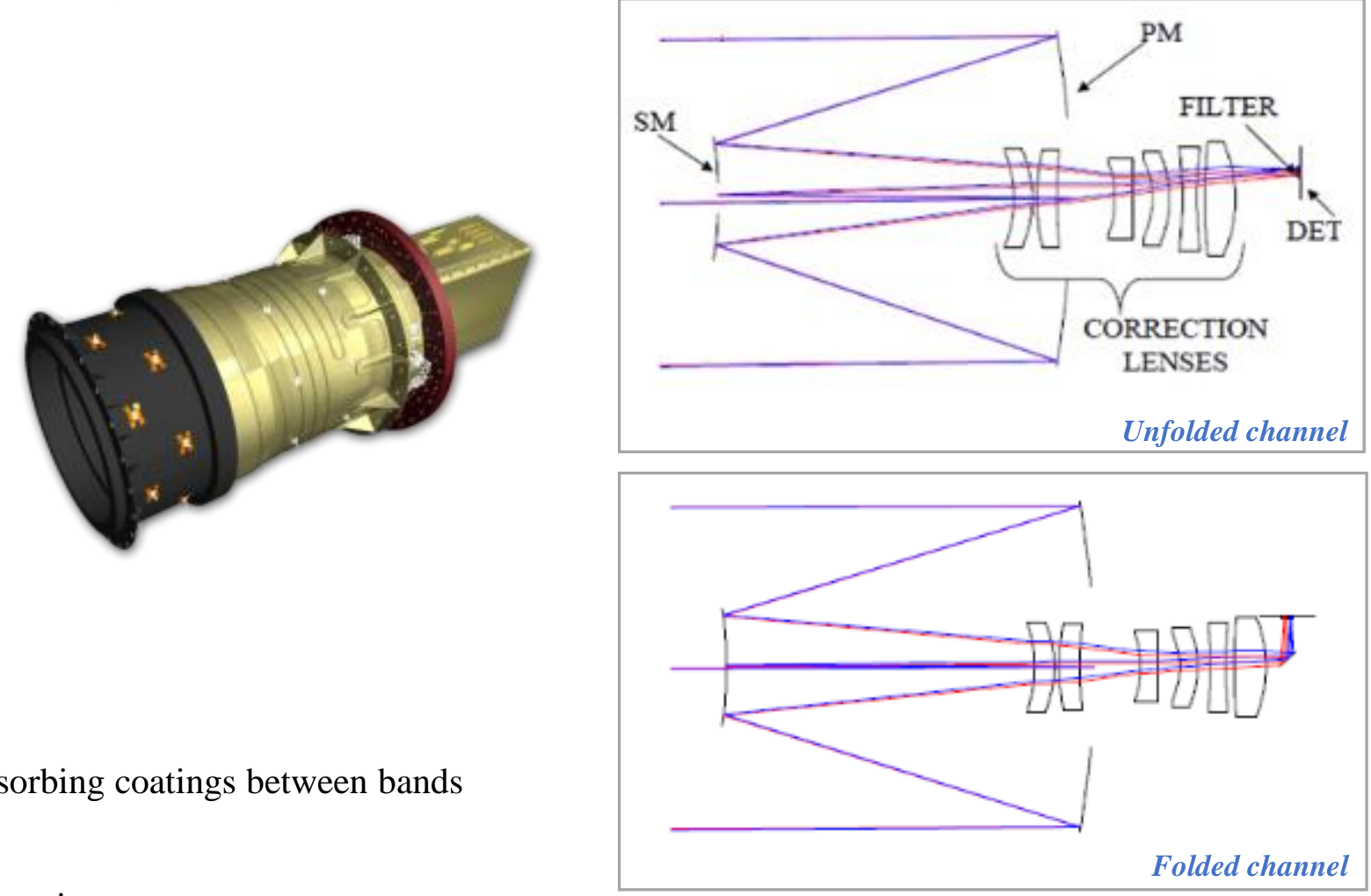

Ven $\mu$ s objective optical lay-out 
VEN $\mu S$ SUPER SPECTRAL CAMERA
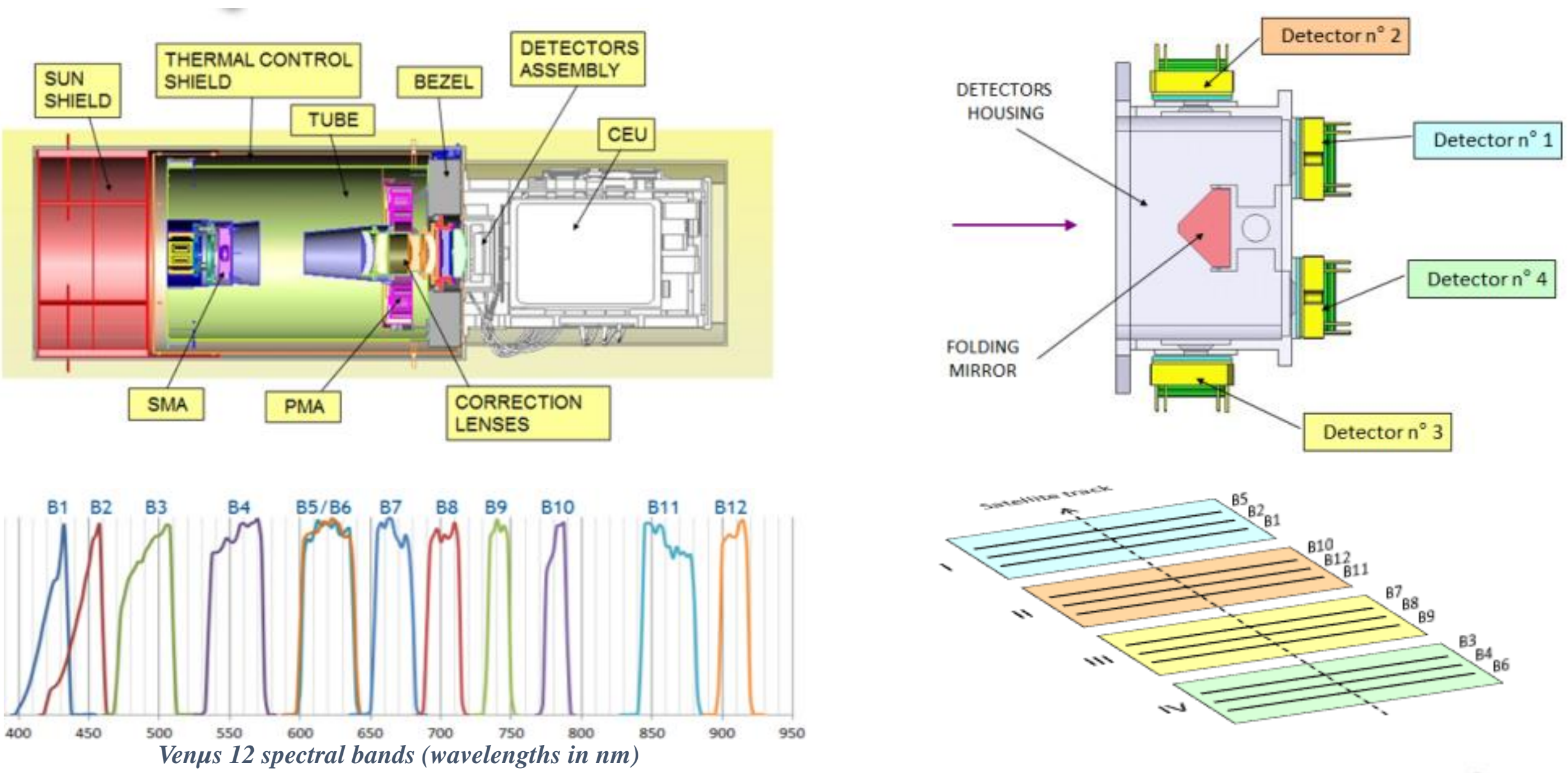


\section{CAUSE OF VEN $\mu$ S STRAY-LIGHT}

- No absorbing coating between detector rows

- Probable non-specular response of the detector close to useful area

- Change in the filter concept (consecutive to the decision to switch to butcher-block filters)

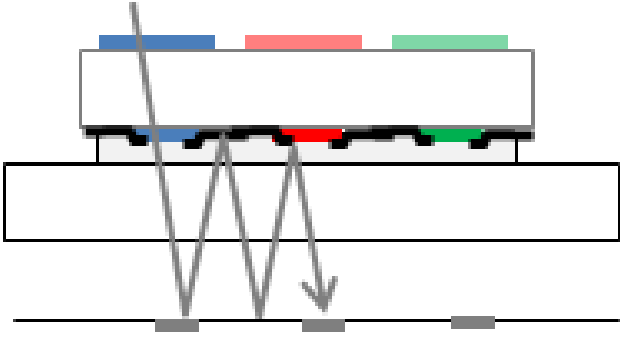

Initial concept: filters are outside detector cavity

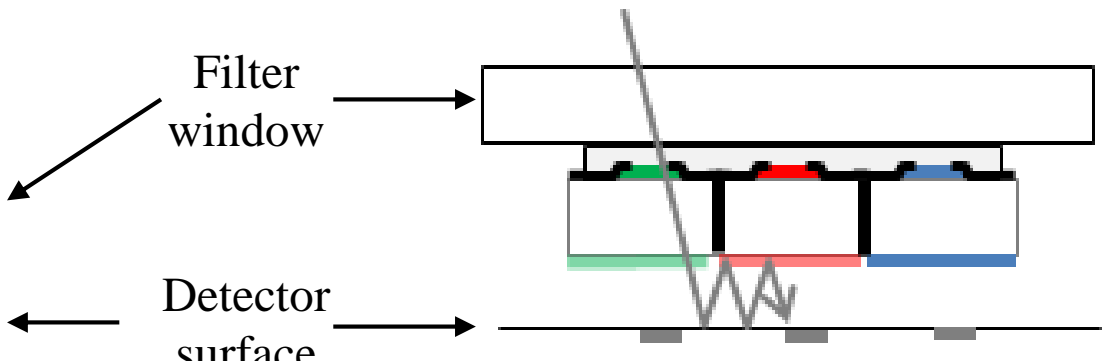

Final concept: no absorbing coating facing the detector 


\section{TYPES OF STRAY-LIGHT}

\section{Local stray-light (SL1)}

Caused by scattering of surfaces of the instrument and multiple reflexion on detectors, filters, window.

$\rightarrow$ generates a low intensity but large blurring effect on the edges of high radiance targets

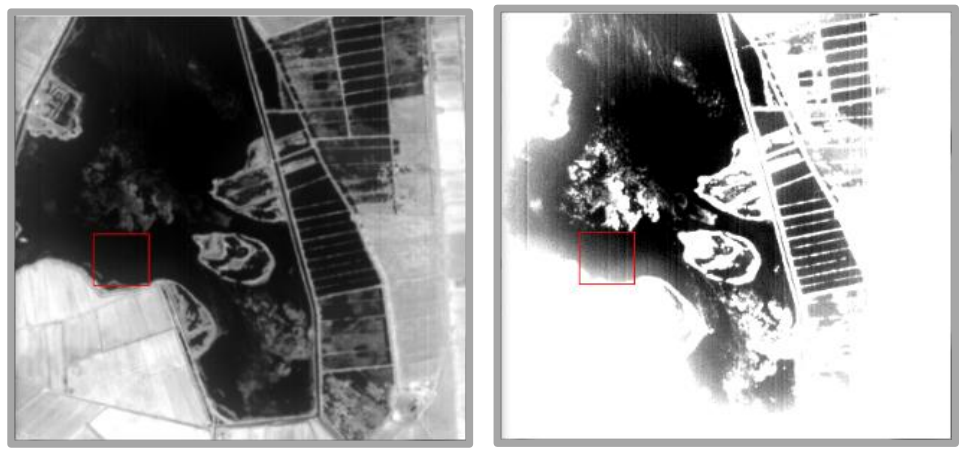

SL1 stray-light on B12 (Maccarese sea shore, Italy)

\section{Cross-talk ghosts (SL2)}

Caused by reflection of light from a band to another band of the same tri-detector

$\rightarrow$ generates a blurring replication of the landscape +-150 pixels above/below

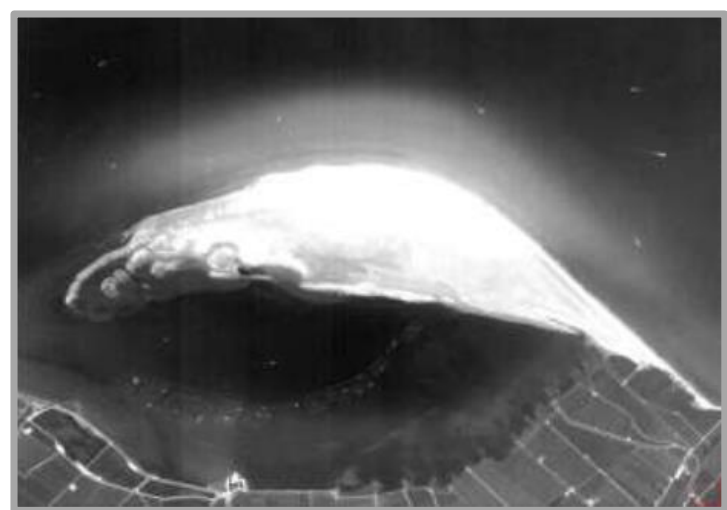




\section{Stray-light ground measurement campaign \& modeling of stray-light}




\section{Type 1 stray-light characterization set-up}

\section{TDI constraint}

Dynamic operation necessary:

- moving targets (several shapes and sizes used) at the collimator focus - uniform illumination over wide area required

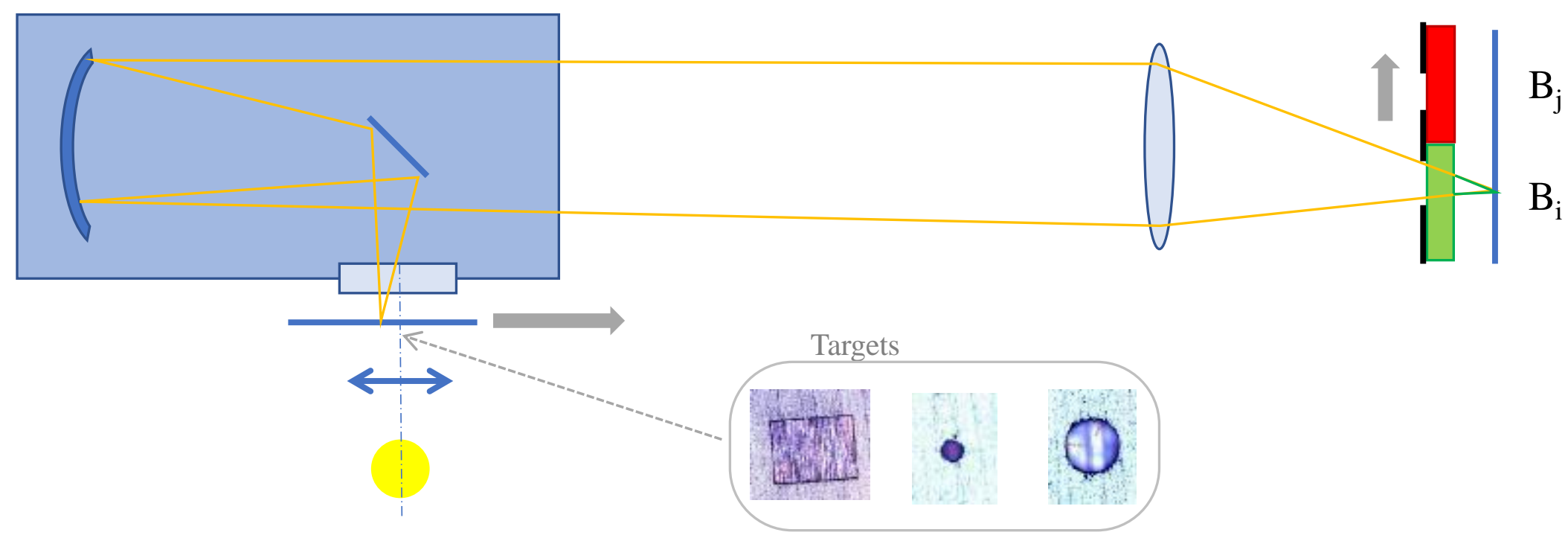




\section{Type 1 stray-light characterization}
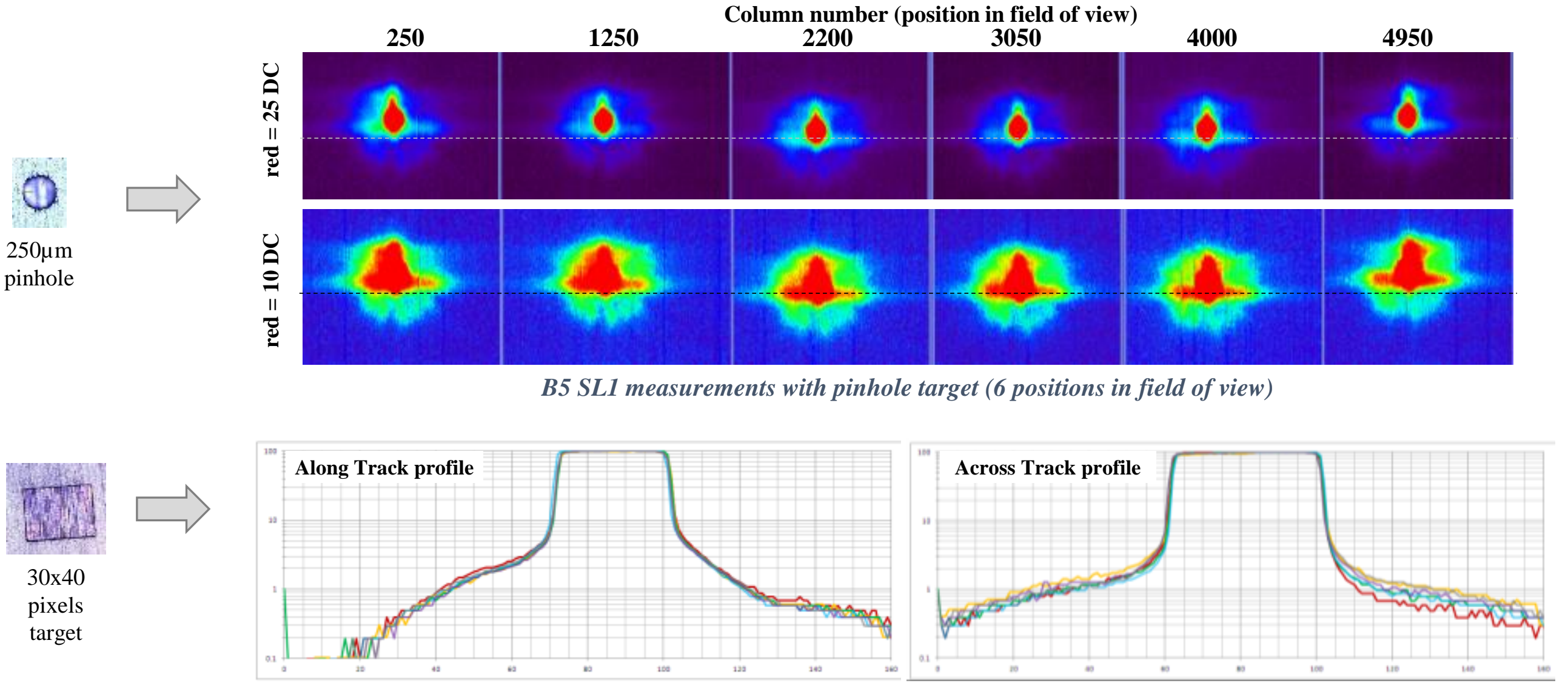

SL1 on B5 with 30x40 target. The colors represent 6 different positions within field of view

$30 \times 40$

pixels

target 


\section{Type 1 stray-light (SL1) modeling}

Principle: computation of a global MTF including SL1 instead of trying to separate SL1 from diffraction

Major points

- Phenomenon must be modeled by a convolution: shall be stable or slowly variable within field-of-view

- Aliasing shall be taken into account, since system MTF is relatively high (0.15)

- Since the source is a disc (a pinhole), its FT is a Bessel function: no frequential info close to nul values of the function

Why not use a point source?

Technical reasons (not enough signal in point source)

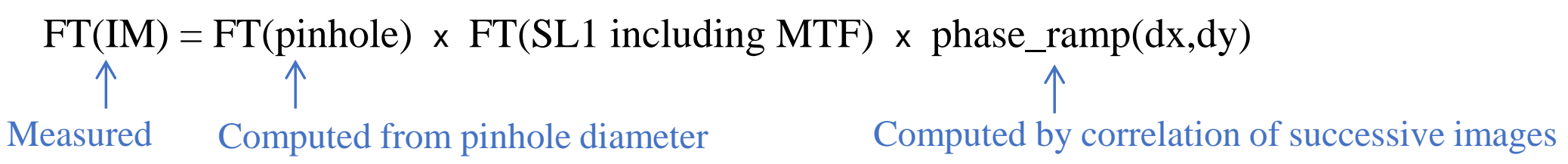

IM = image

FT $=$ Fourrier Transform 


\section{Type 1 stray-light (SL1) modeling}

Taking aliasing into account

- The unknown is a FT(SL1) matrix, ranging from $-\mathrm{fe} / 2$ to $+\mathrm{fe} / 2$

- Assumption: $\operatorname{MTF}(\mathrm{f}>\mathrm{fe})=0$

- To avoid aliasing, frequencies up to fe shall be computed $\rightarrow 4$ times more points

- 4 acquisitions needed, shifted by a sub-pixel distance

- To take noise into account, 10 acquisitions are performed

- Each point represents the contribution of 4 elements in the equation: (fx,fy) and replicas $(f x+f e, f y),(f x, f y+f e),(f x+f e, f y+f e)$

\section{Taking into account zeroes of the source}

- The FT of a disk is an Airy Function. The first zeroes follow this sequence: 1.22, $2.23,3.24,4.24,5.24$

- To get frequential info in these positions, a second circular source is used. The ratio of the dimensions of the sources is chosen in such a way that the first zeroes do not coincide: 0.846 is the optimal value for this ratio.

- The same series of measurements is performed with the second source.

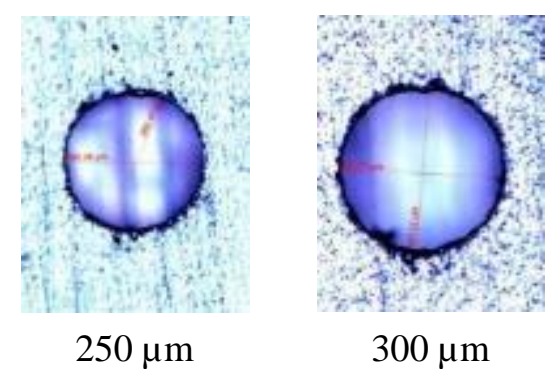




\section{Type 1 stray-light (SL1) modeling}

\section{Resolution of the system}

10 measurements, 4 unknowns

Images $128 \times 128$ are used $\rightarrow 16384$ least squares

Ground measurement campaign (2014)

10 measurements $\times 2$ pinholes $\times 6$ positions in field-of-view $\times 12$ bands $(\times 2$ TDI configurations)

$=$ more than 2000 measurements 


\section{Type 2 stray-light (SL2) characterization set-up}

Isolating sources of stray-light

Use of filter in the collimator focal plane

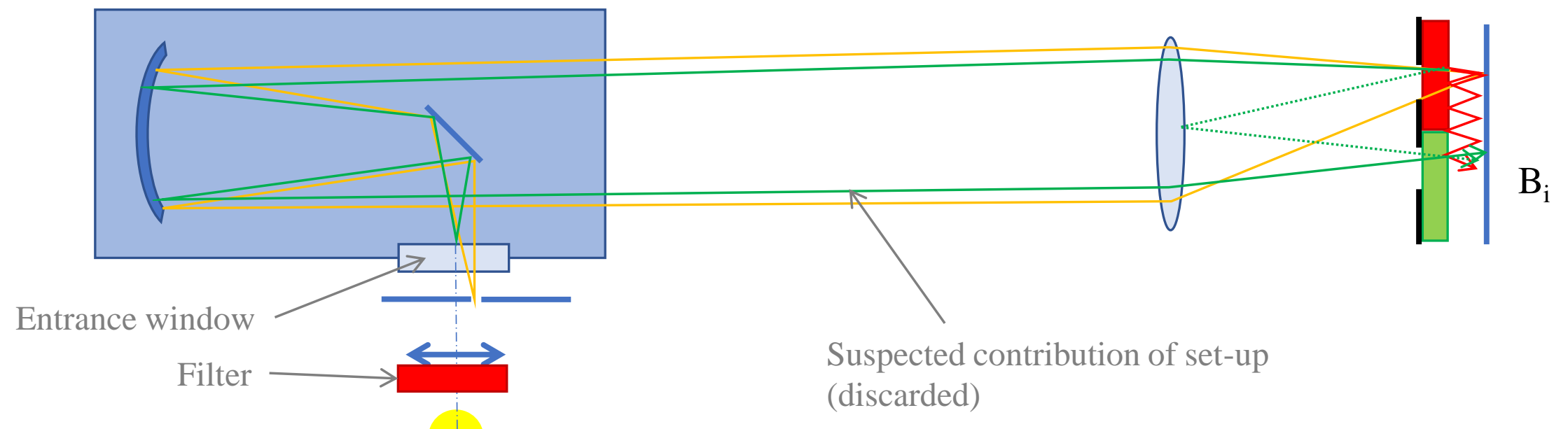




\section{Type 2 stray-light (SL2) characterization set-up}

Isolating sources of stray-light

Use of filter in the collimator focal plane

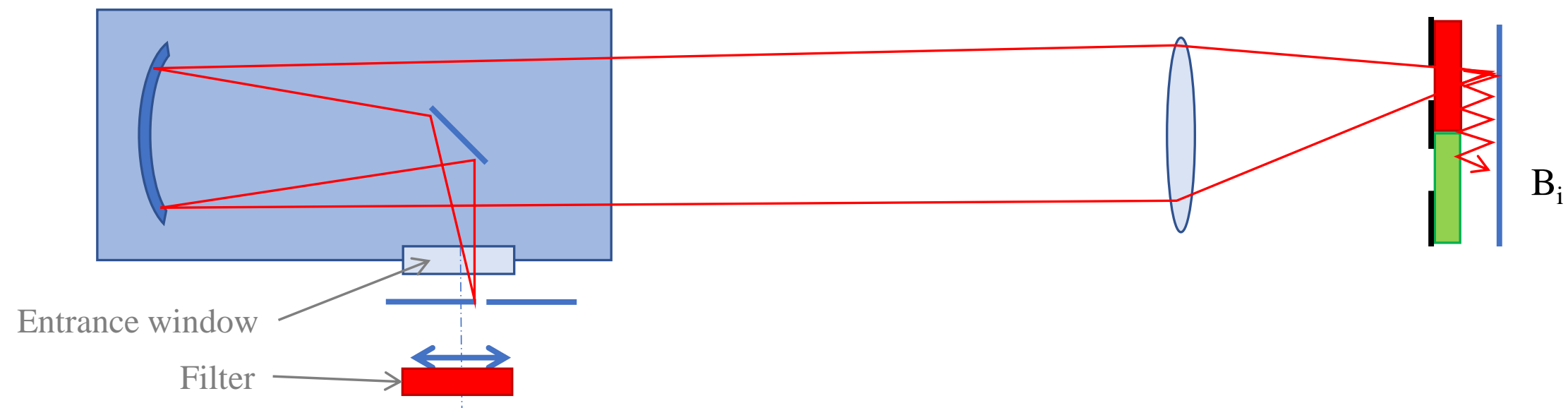




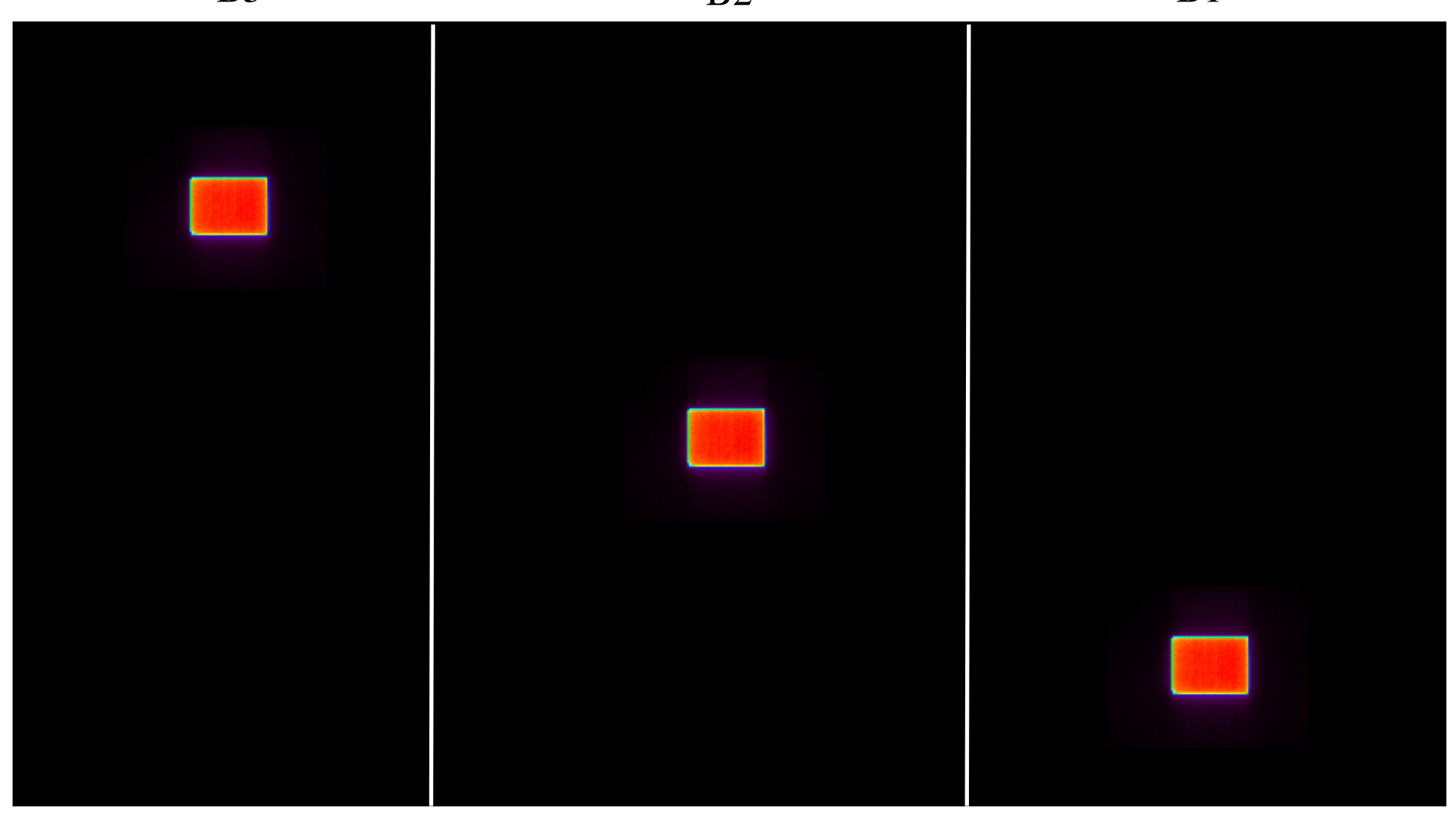


B2

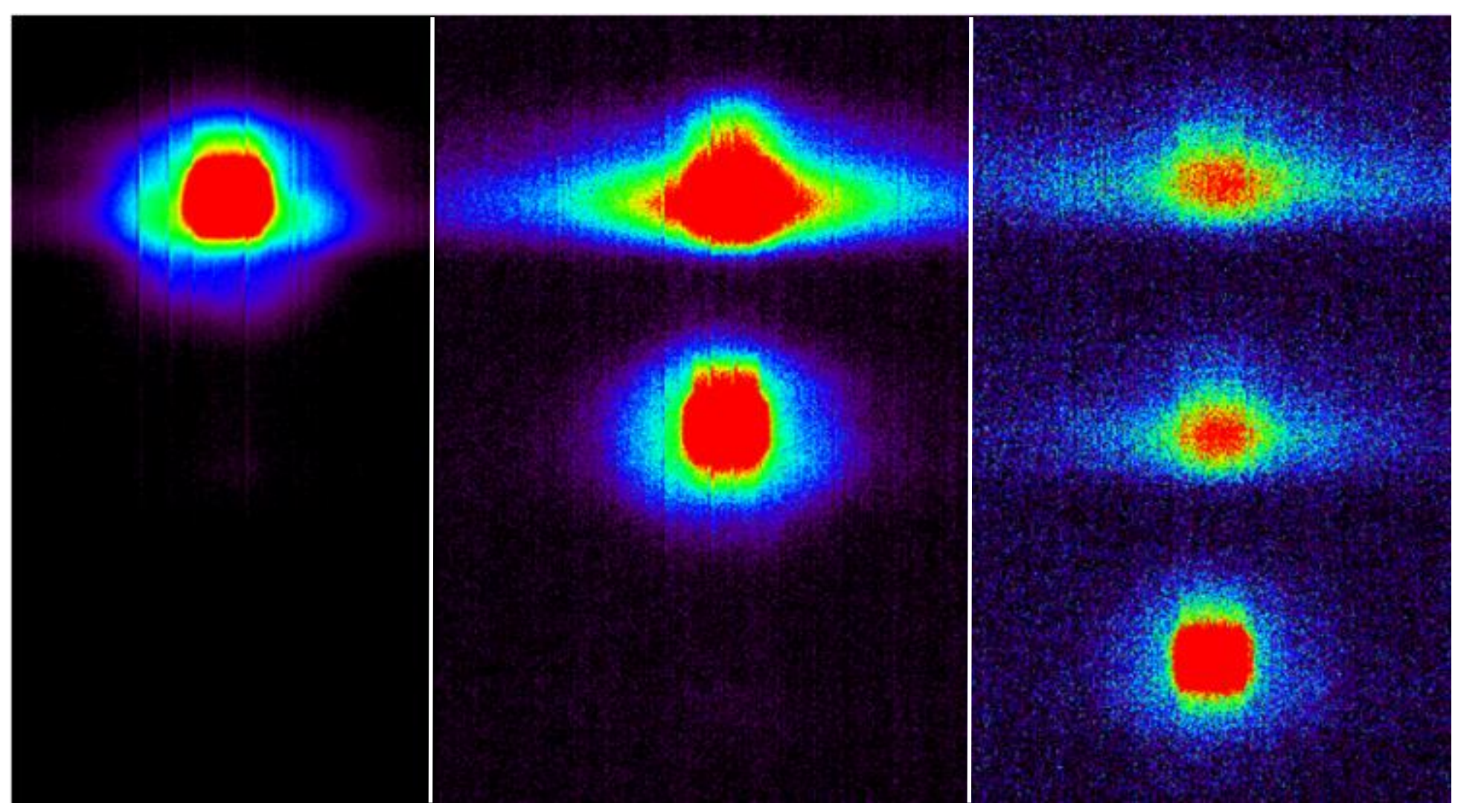

\section{B1}

cnes . . 


\section{Type 2 stray-light (SL2)}

\section{Major points}

- Bands are polluted by optical cross-talk coming from simultaneous light from the 2 other bands of the tri-detector

- Substraction from the image of the cross-talk contribution
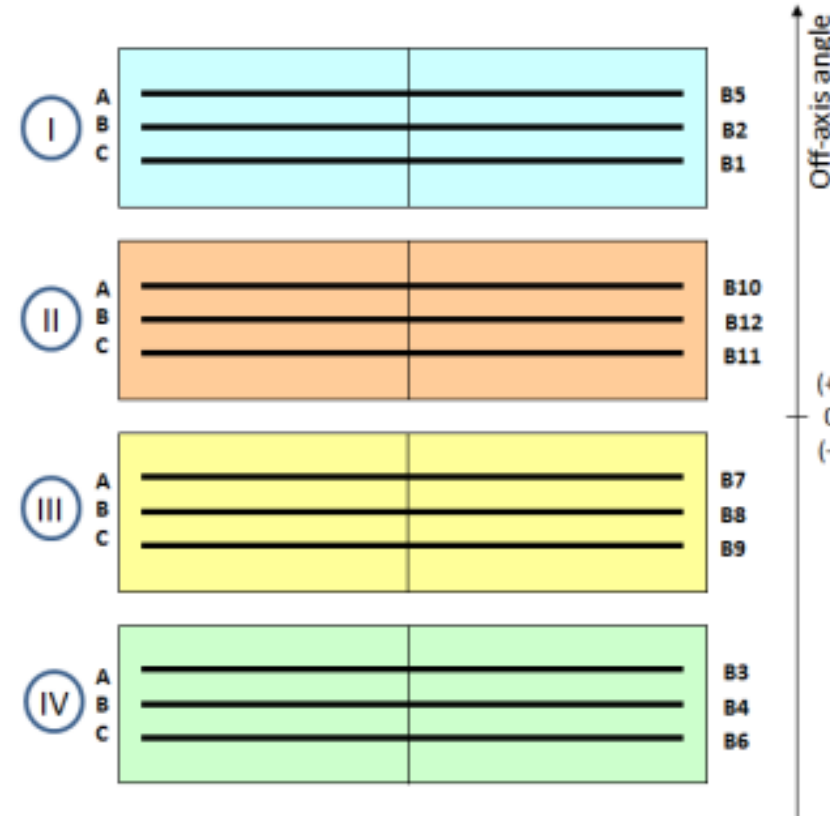


\section{Type 2 stray-light (SL2) modeling}

- From high-energy (saturated) pinhole80 $(80 \mu \mathrm{m}$ diameter) images at center of field-of-view $\rightarrow$ shape of the impulse response of the cross-talk

- From target D (30x40 pixels) $\rightarrow$ centering and amplitude of the impulse response for optimization

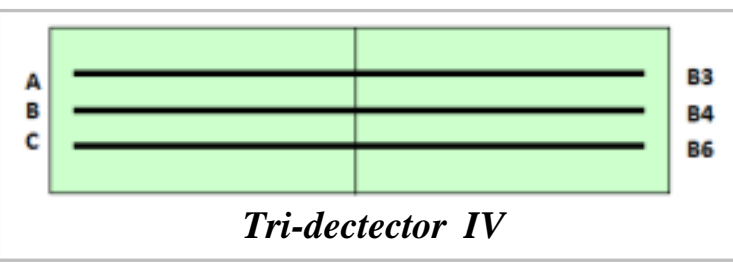

- Apply the calculated impulse response to other patterns for validation and final tuning of the amplitude

- Extrapolation in the rest of the field-of-view from centering and amplitude laws
Pinhole80

(SEM)

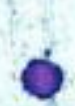

TargetD

(SEM)

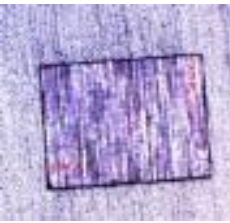

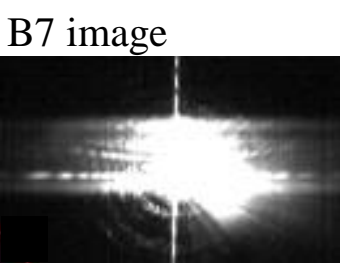

B3 image

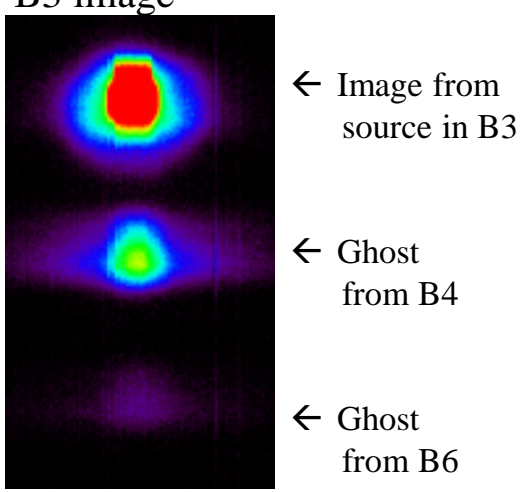




\section{Stray-light correction}

\section{SL1 Corrected image $\mathrm{Bi}=($ Source image $\mathrm{Bi}) \otimes \mathrm{FT}\left(\mathrm{F}_{\mathrm{Bi}}\right)$}

$\mathrm{F}_{\mathrm{Bi}}$ is a frequential filter that represents the SL1 considered as an MTF

SL2 Corrected image Bi $=($ Source image Bi $)-\sum_{B j}($ Source image Bj $) \otimes F_{B j \rightarrow B i}$ $\mathrm{F}_{\mathrm{Bj} \rightarrow \mathrm{Bi}}$ is a spatial filter that represents the spreading of the cross-talk ghosts from $\mathrm{Bj}$ impacting $\mathrm{Bi}$ 


\section{Performances Results}


Sample examples from B2 spectral band

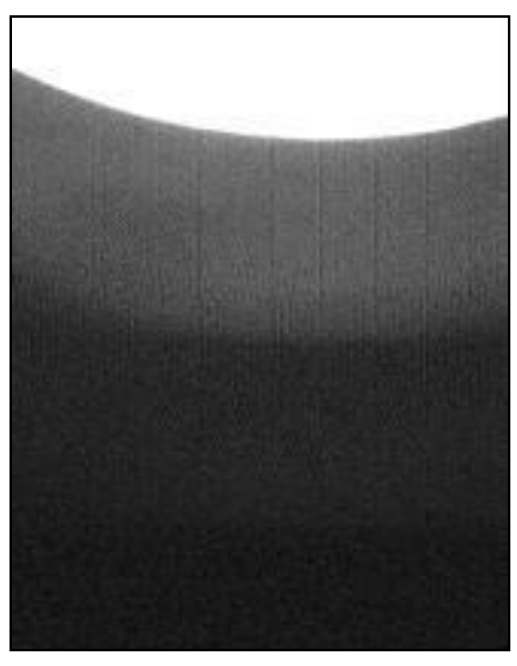

The moon

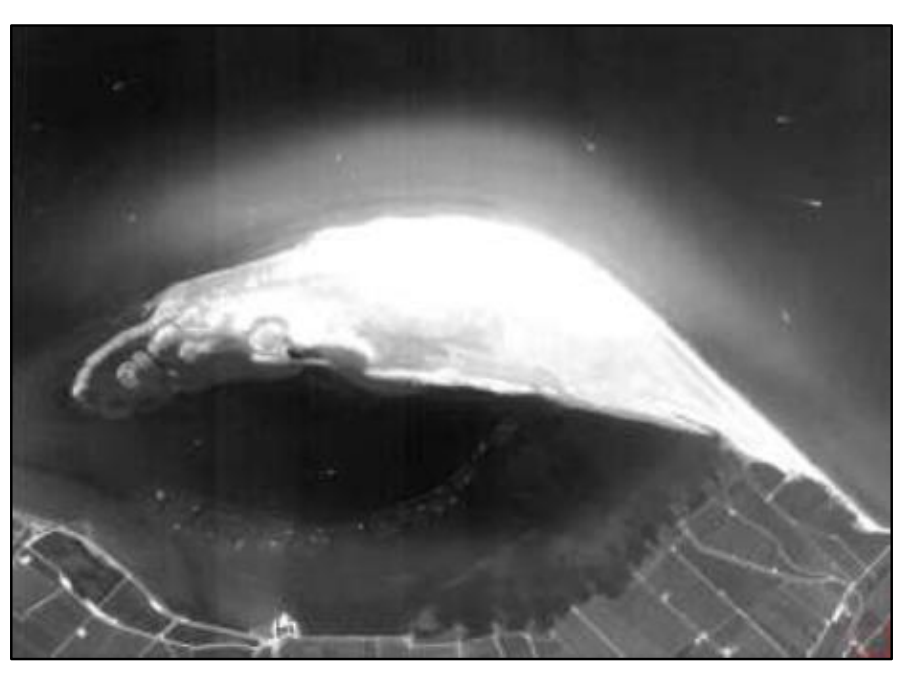

Delta Ebro beach and sea shore

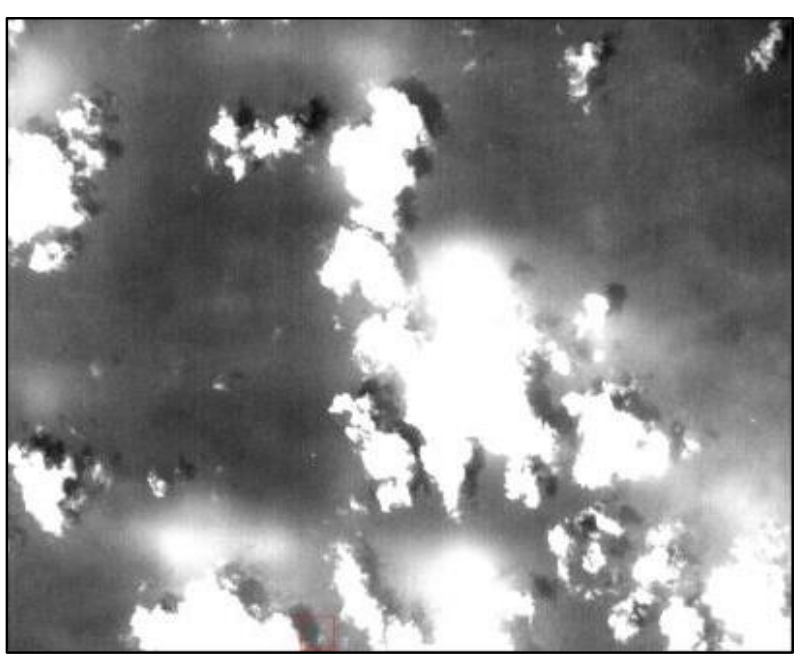

Clouds over Pacific ocean 
Sample examples from B2 spectral band

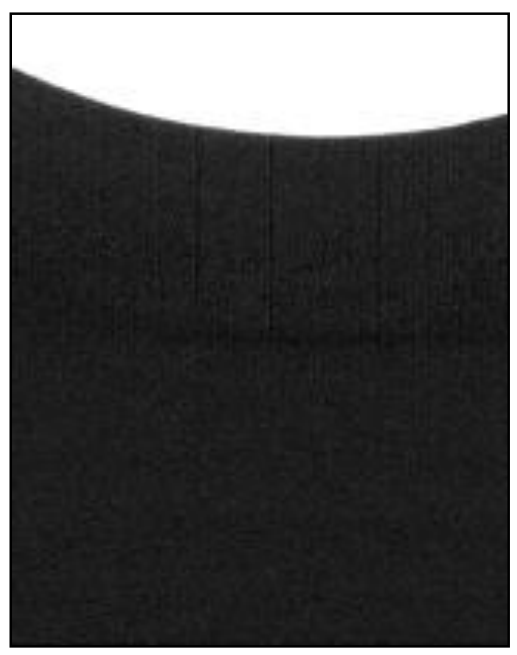

The moon

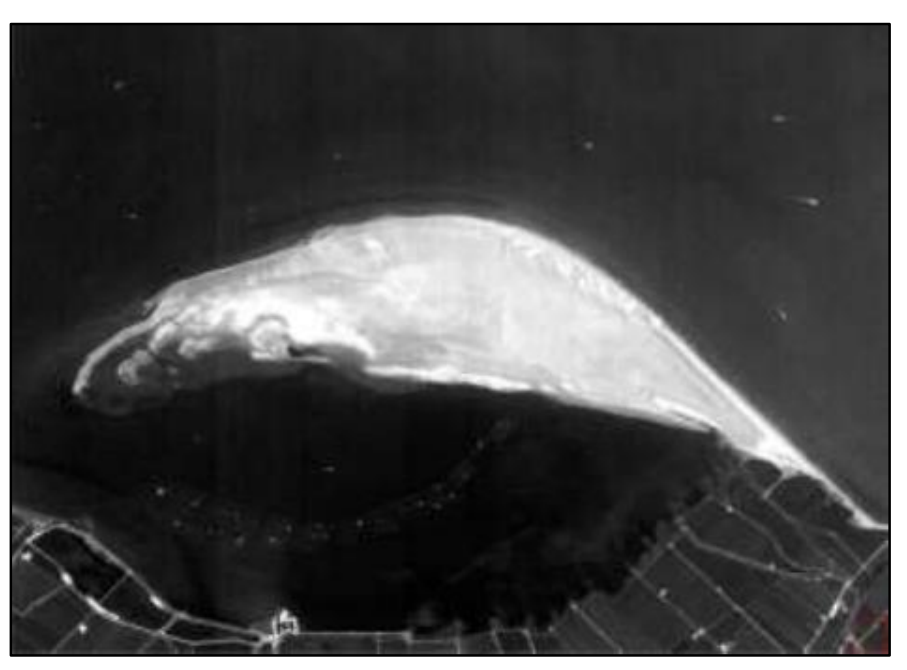

Delta Ebro beach and sea shore

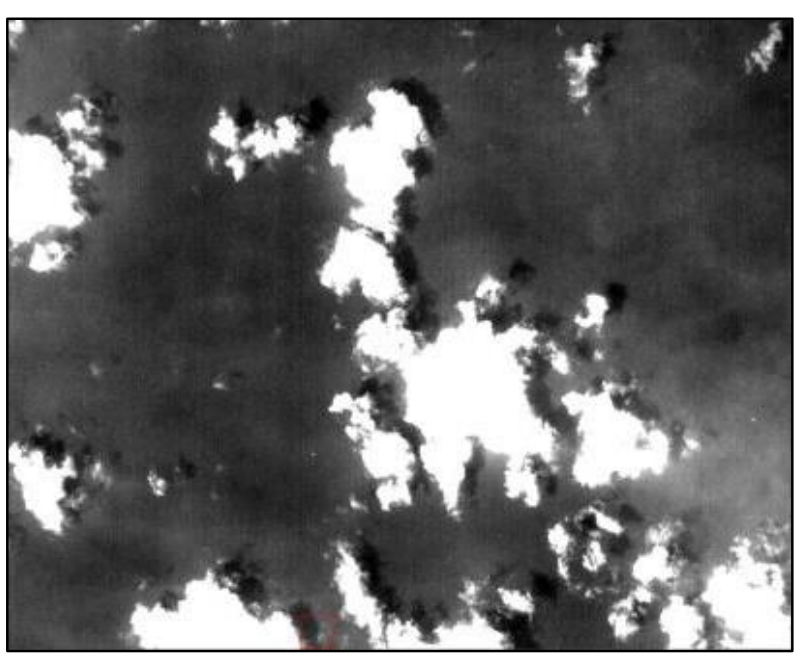

Clouds over Pacific ocean 


\section{STRAY-LIGHT CORRECTION PERFORMANCE}

Stray-light correction: remove local stray-light and cross-talk (ghosts) stray-light

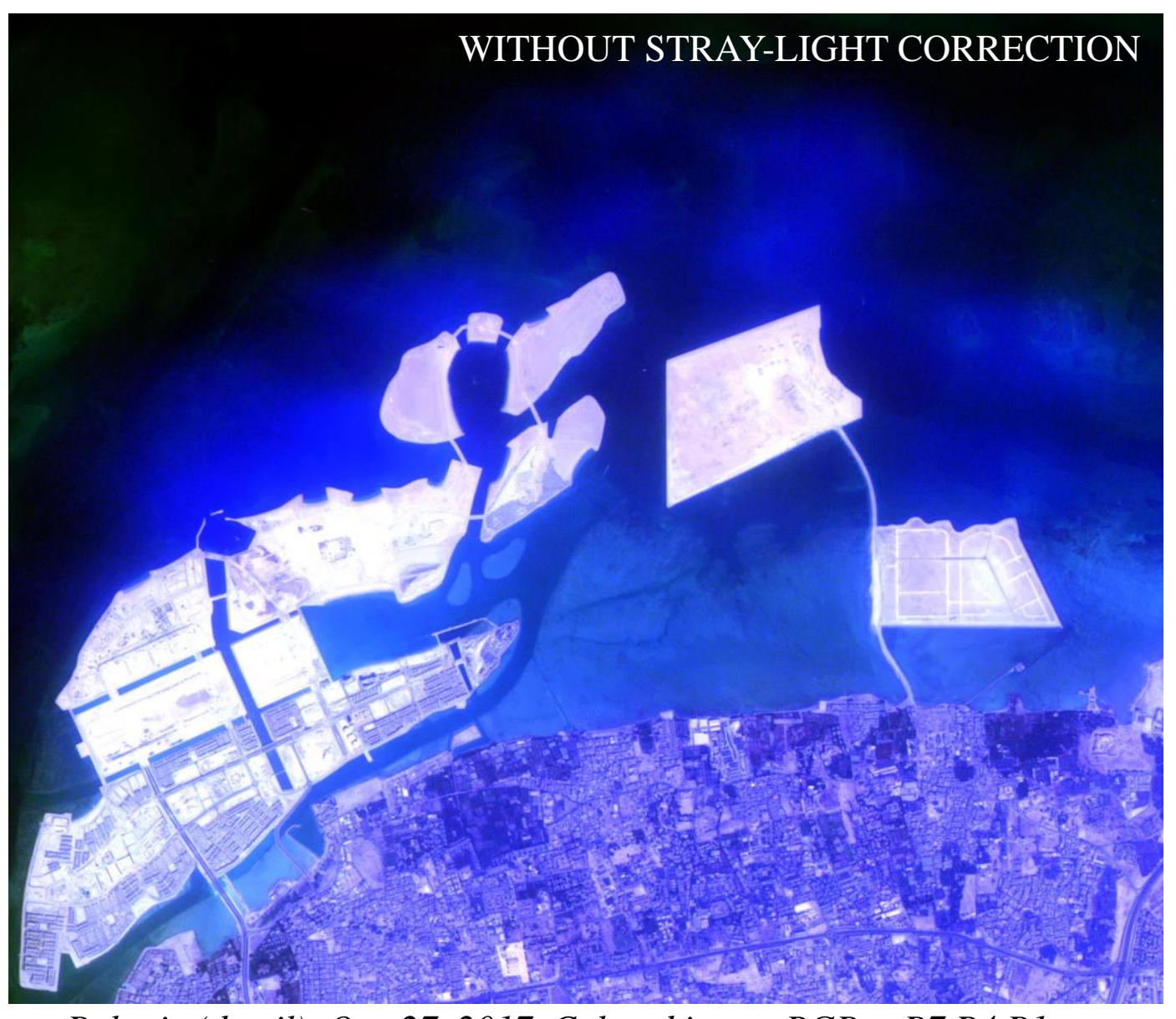

Bahrein (detail), Oct. 27, 2017, Colored image $R G B=B 7$ B4 B1 


\section{STRAY-LIGHT CORRECTION PERFORMANCE}

Stray-light correction: remove local stray-light and cross-talk (ghosts) stray-light

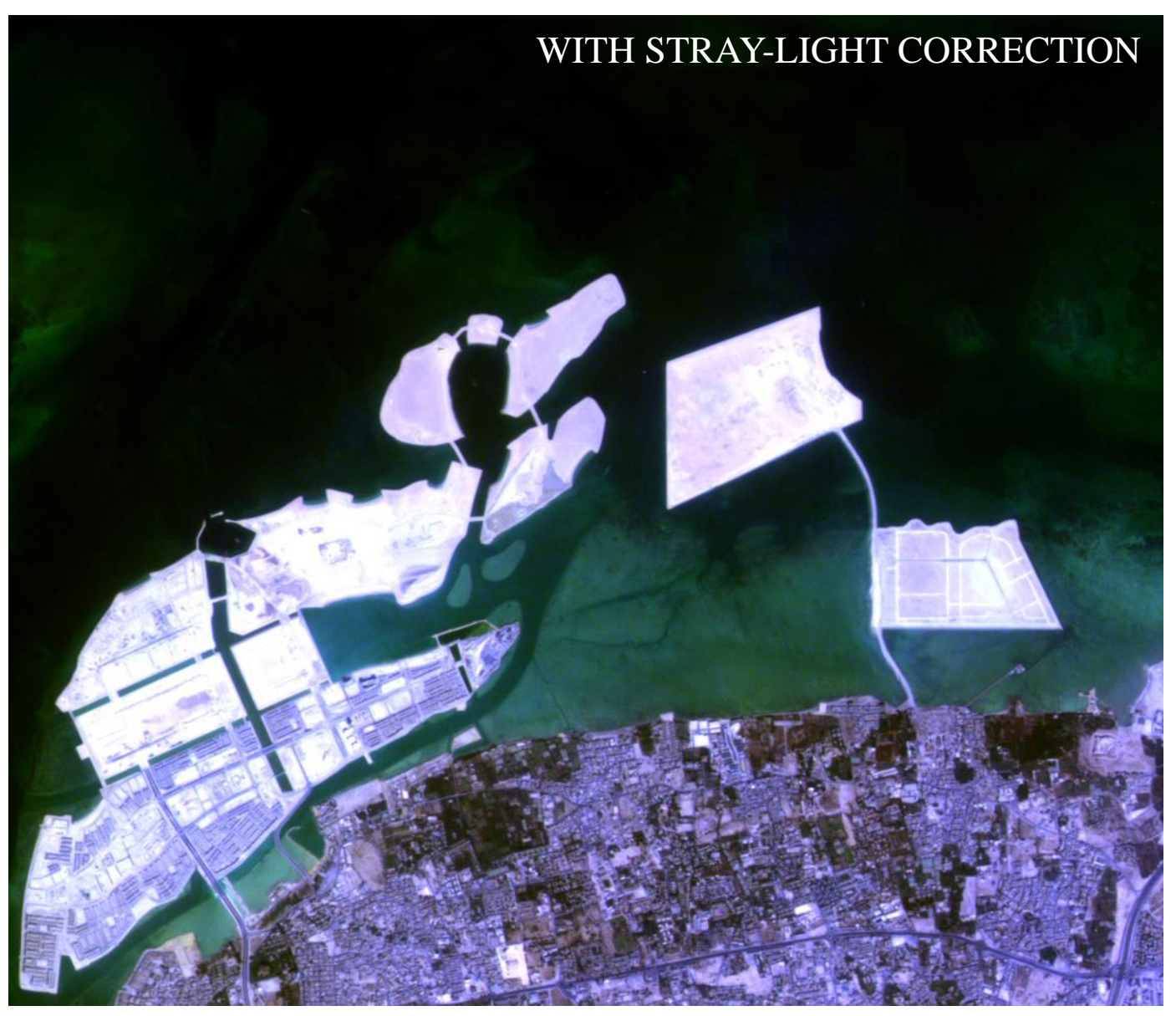

Bahrein (detail), Oct. 27, 2017, Colored image RGB = B7 B4 B1 


\section{STRAY-LIGHT CORRECTION PERFORMANCE AND CONCLUSIONS}

Ebro delta, Spain (zoom) - Venus Aug. 18, 2017

- Minor tunings performed during IOT: global in-flight performances are in line with ground tests

$\checkmark$ temporal stability of the phenomena

$\checkmark$ validation of the assumptions made for modeling

- SL1 (local stray-light): SNR required by the mission is fulfilled after correction at 10 native pixels from typical bare soil / vegetation transition

- SL2 (cross-talk ghosts) performance assessment from in-flight measurements: worst case stray-light residue is comparable to instrument noise (0.5 DC)

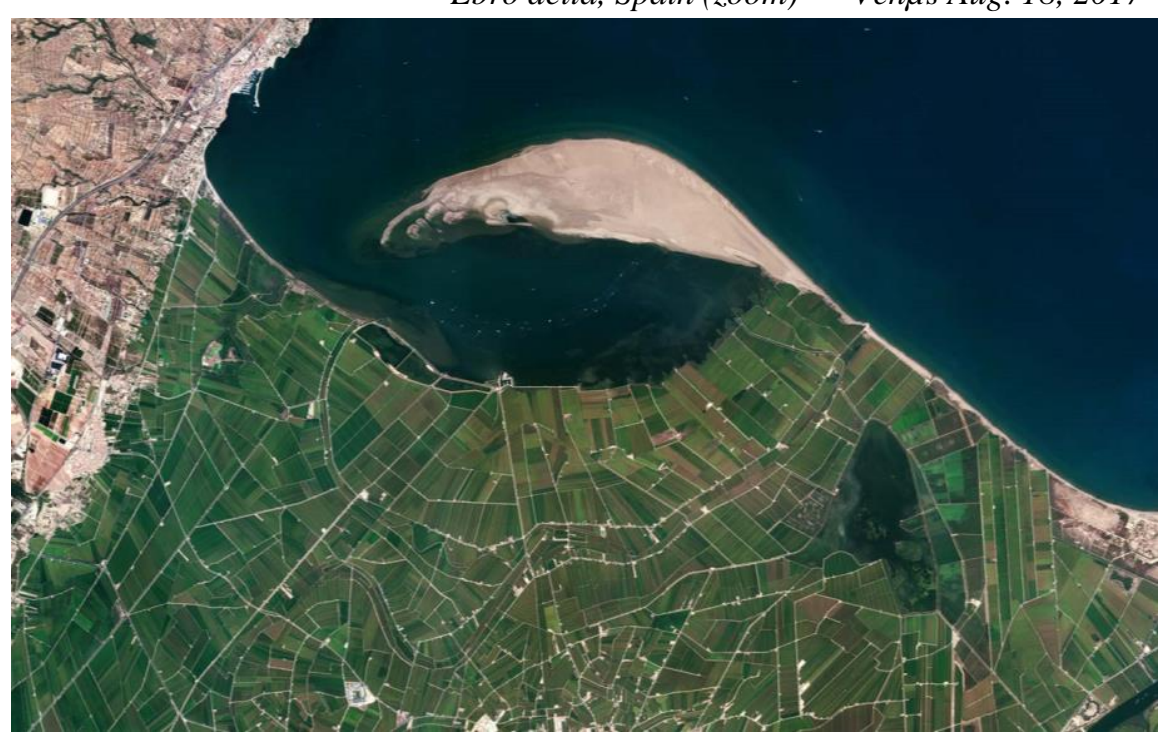

$\checkmark$ Stray-light correction performance is highly satisfactory thanks to a great team work: CNES experts, and high level of commitment and of expertise by ELOP

$\checkmark$ Overall image quality is good, and the products match scientific expectations, except for some « difficult » sites 


\section{Additional slides}




\section{CONCLUSIONS}

$\checkmark$ Overall image quality is good, and the products match scientific expectations, except for some «difficult » sites

Stray-light correction performance is highly satisfactory

$\checkmark$ Radiometric calibration

- good performance for spectral bands B3 to B11

- not accurate enough for deep blue bands (B1 and B2)

- will be updated for water vapour band (B12)

$\checkmark$ Reprocessing: end of 2018 with updated configuration (enhanced geometric performance and B12 calibration)

$>$ The capability to image the Moon brings valuable information for radiometric calibration and performance assessment

Download Ven $\mu$ s products (free access) on www.theia-land.fr 
THE PRODUCTS
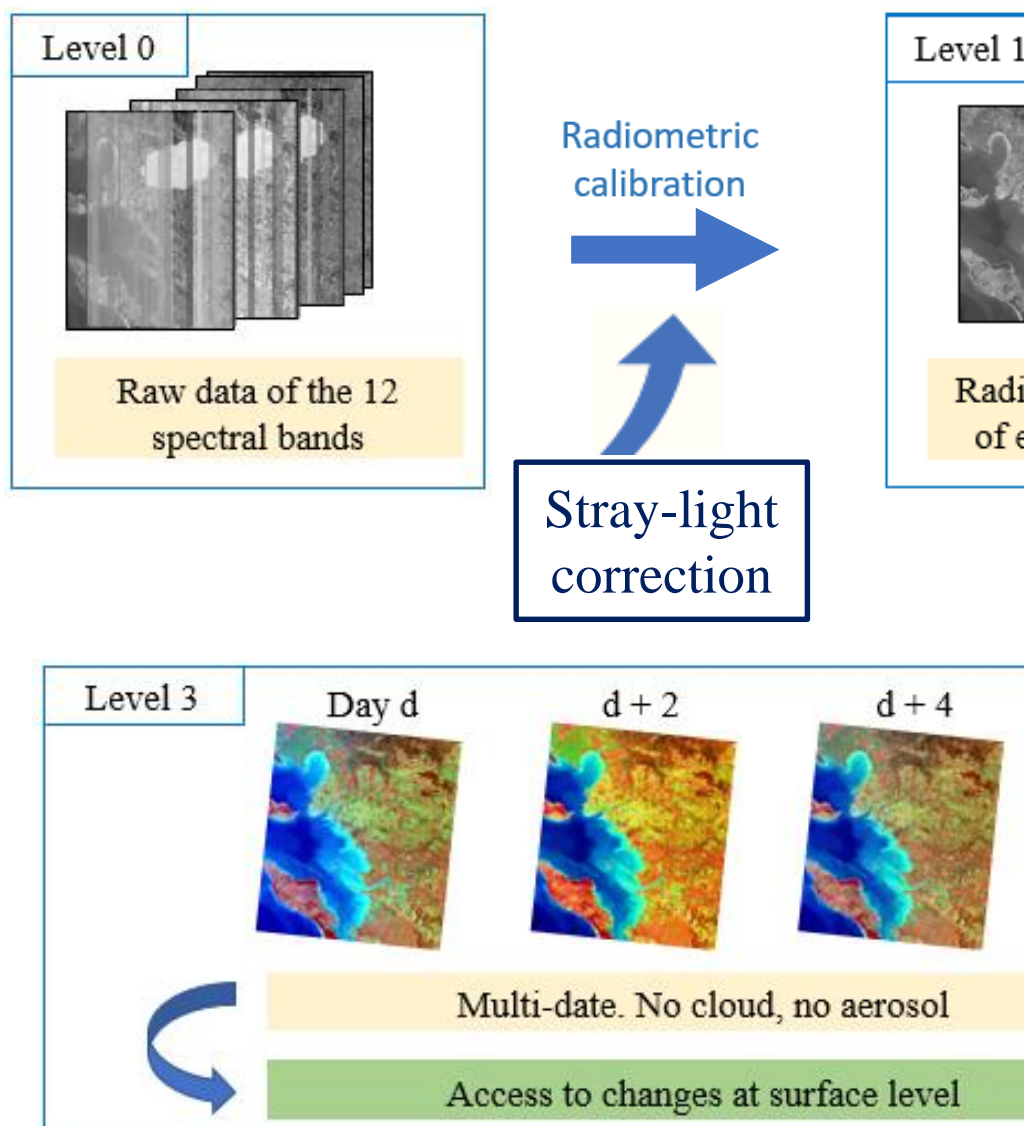

Multi-date. No cloud, no aerosol

Access to changes at surface level
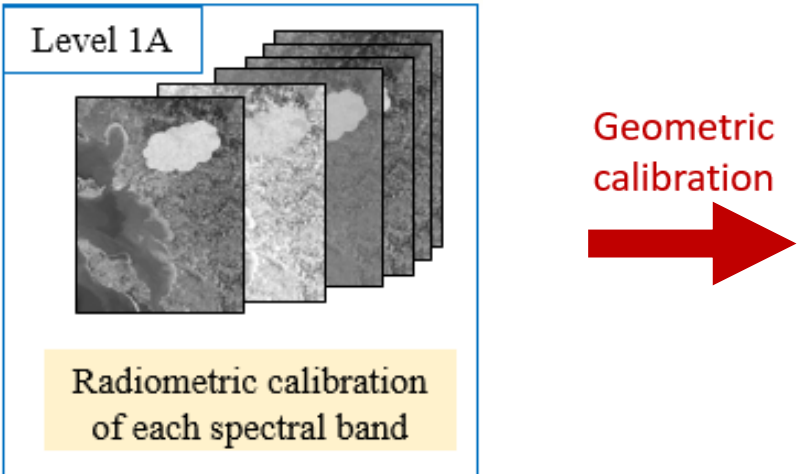

Radiometric calibration

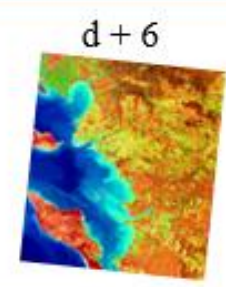

\section{Computation} of time series

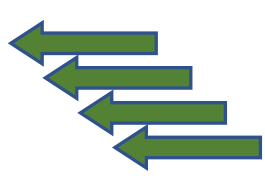

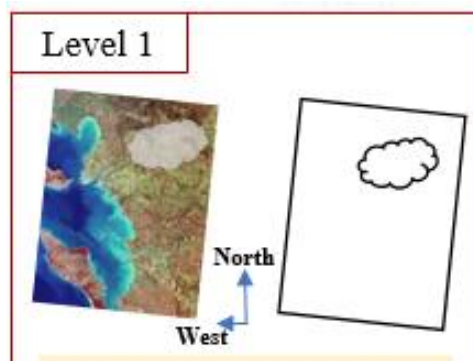

Cartographic projection Top-of-atm. reflectance

Atmospheric correction

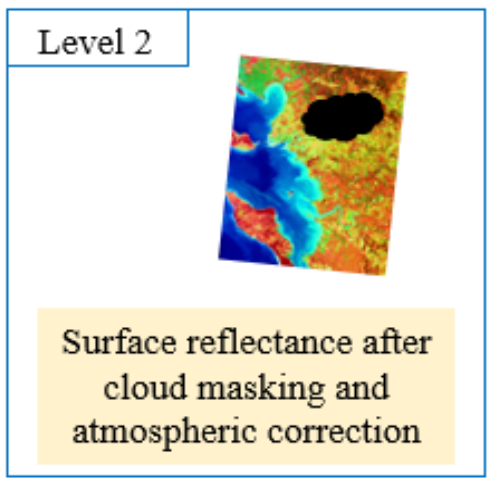




\section{WHICH STRAY-LIGHT ?}

\section{Type 1 stray-light (SL1)}

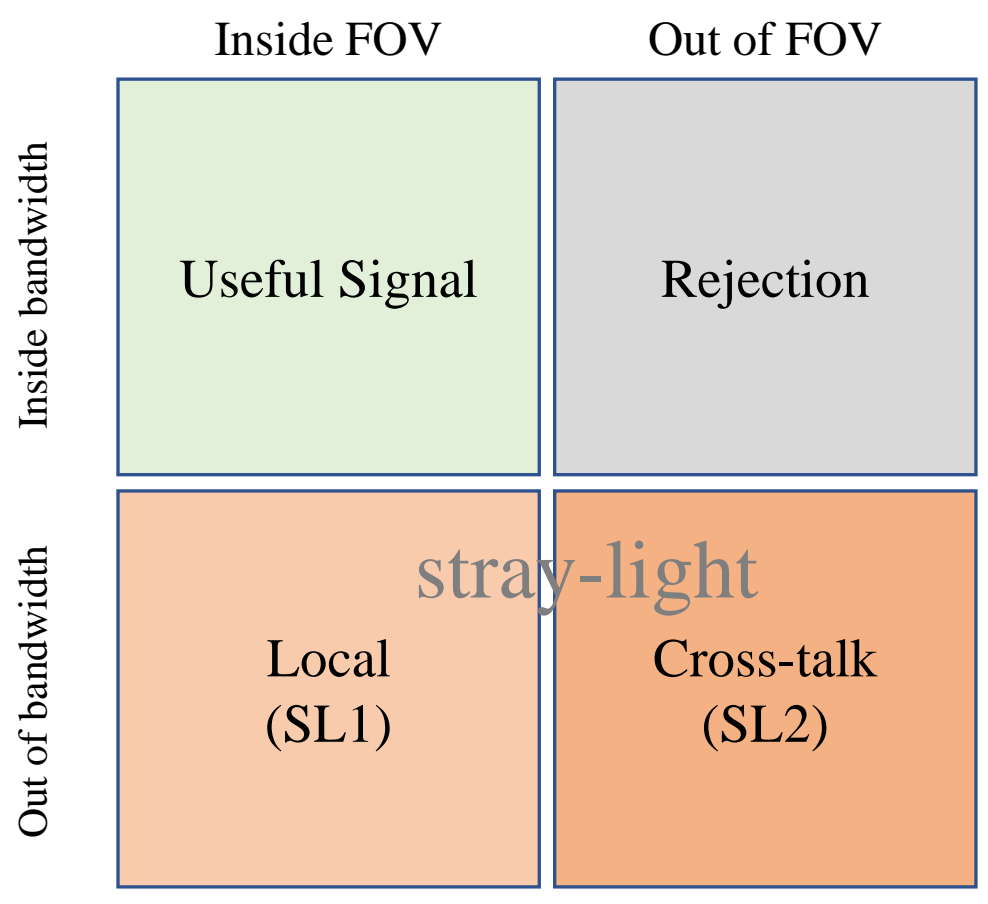

- The detector reflects part of the incoming light, which is reflected back on the detector by different sides of the filters and optical elements

- It can be visualised using point sources

- Circular spot surrounding each light point

- The intensity is low, and depends on the size of the enlighted area

- Expected dissymetry due to the inclination of the beam axis when the enlighted area is at edge of swath

\section{Type 2 stray-light (SL2)}

- Due to multiple reflections between lenses surfaces, filters and elements from the detector block

- Not localized with the image spot

- Different possible shapes: rings (POLDER), ghosts, continuous background 


\section{IMPACT OF CROSS-TALK GHOSTS ON THE MISSION}

Error on TOA radiance due to optical crosstalk as measured with 30x40 pixels target For different types of vegetation, solar zenithal angle $=15$ degrees, standard atmosphere

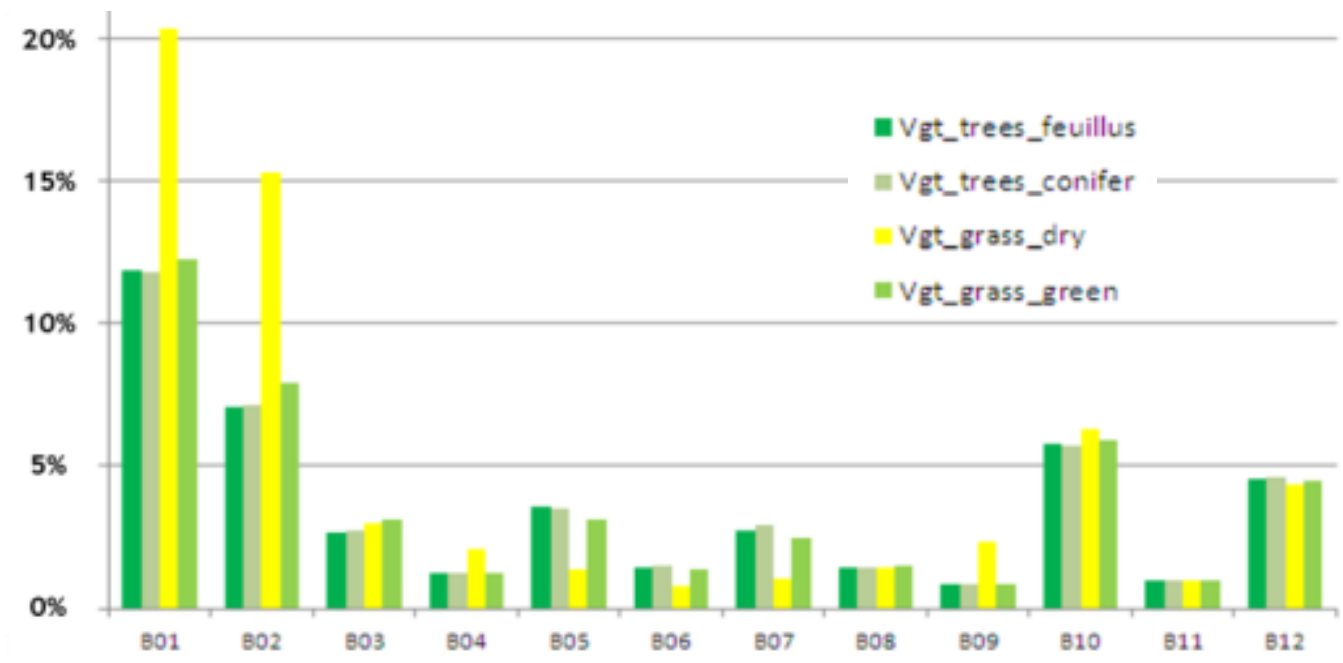

Cannot be neglected !!

$\rightarrow$ Implementation of a ground correction, based on a specific on-ground measurement campaign in 2014

$\rightarrow$ cross-talk is to be taken into account in ground measurements analysis 


\title{
Stray-light correction implementation
}

\author{
(Additional slides)
}




\section{Stray-light correction implementation}

For SL1 and SL2, correction parameters depend on location across track

SL1

$\mathrm{F}_{\mathrm{Bi}}$ depends on column (for B11 and B12 only)

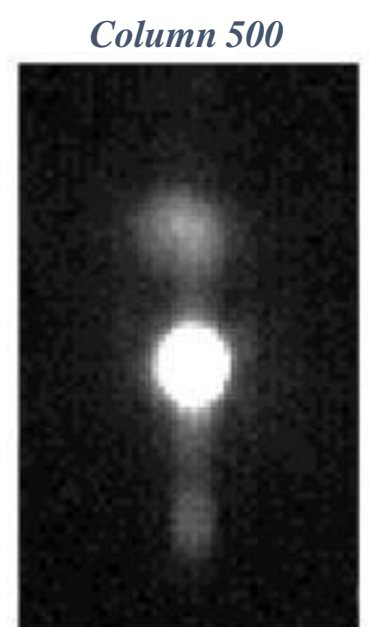

Column 4700

SL1 on B11 with Pinhole 300

Variability in the field of view
SL2

Amplitude and location of crosstalk depend on column

Column

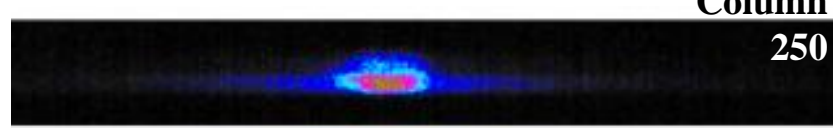

1250

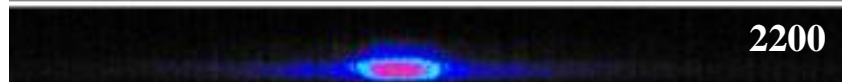

3050

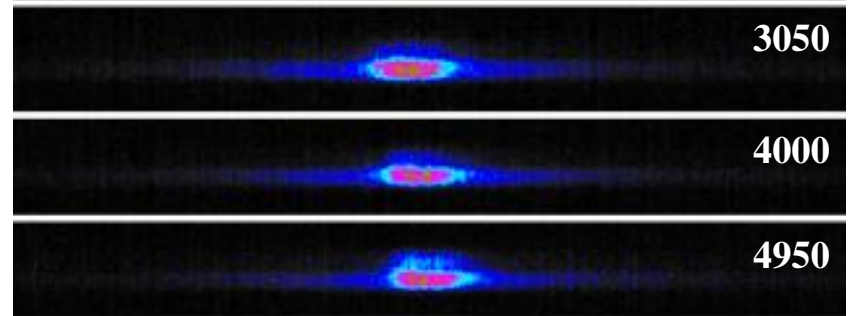

Shift in columns between crosstalk generator and cross-talk position ( 4 pixels every 1000 pixels across track)

correction (convolution) of SL1 and SL2 by vertical strips, using a specific filter for each strip

$>$ implemented in radiometric processing (product level L0 to L1A) of Ven $\mu$ s image production center 


\section{Performances} Results

\section{(Additional slides)}




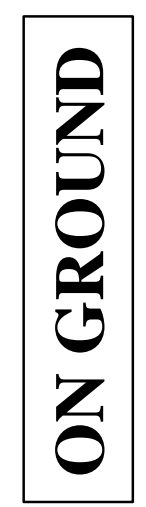

Test pattern

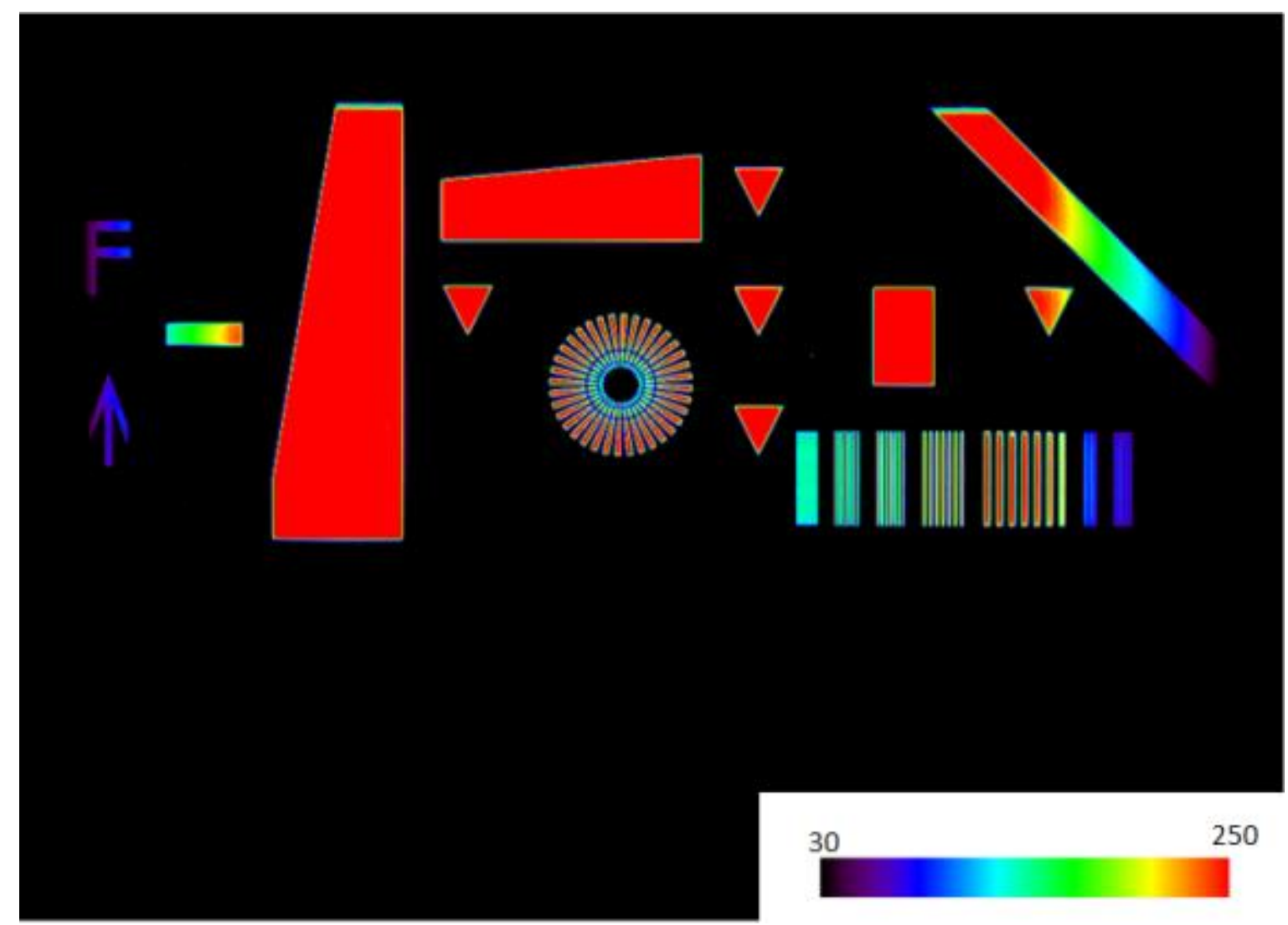




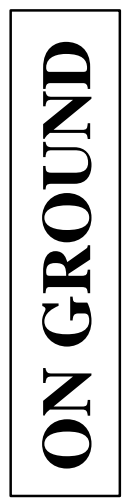

\section{Uncorrected B7 image of test pattern}

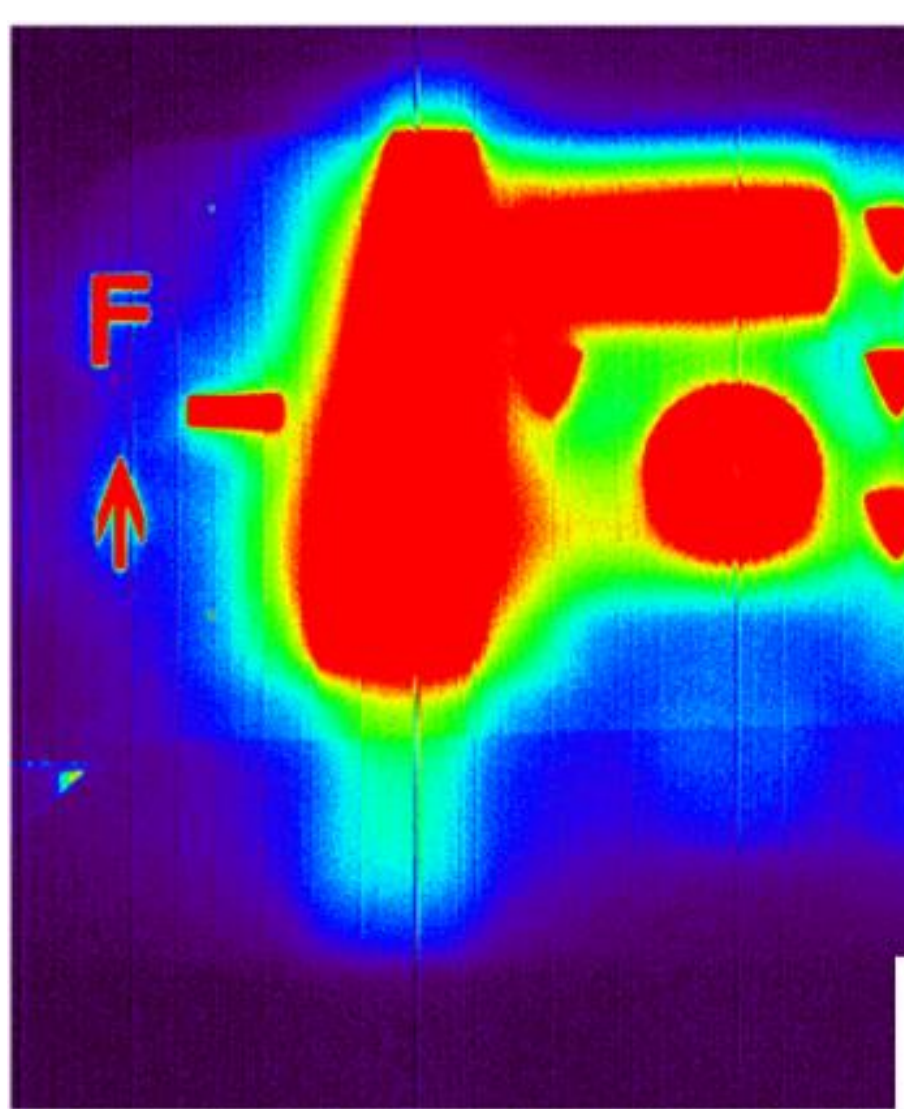

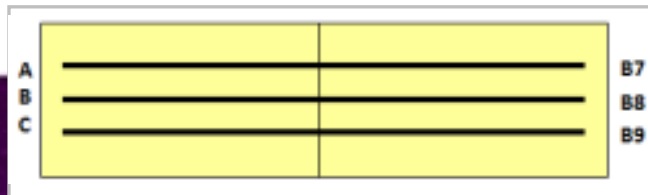

Tri-dectector III 


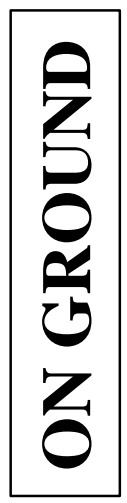

B7 image corrected from SL2

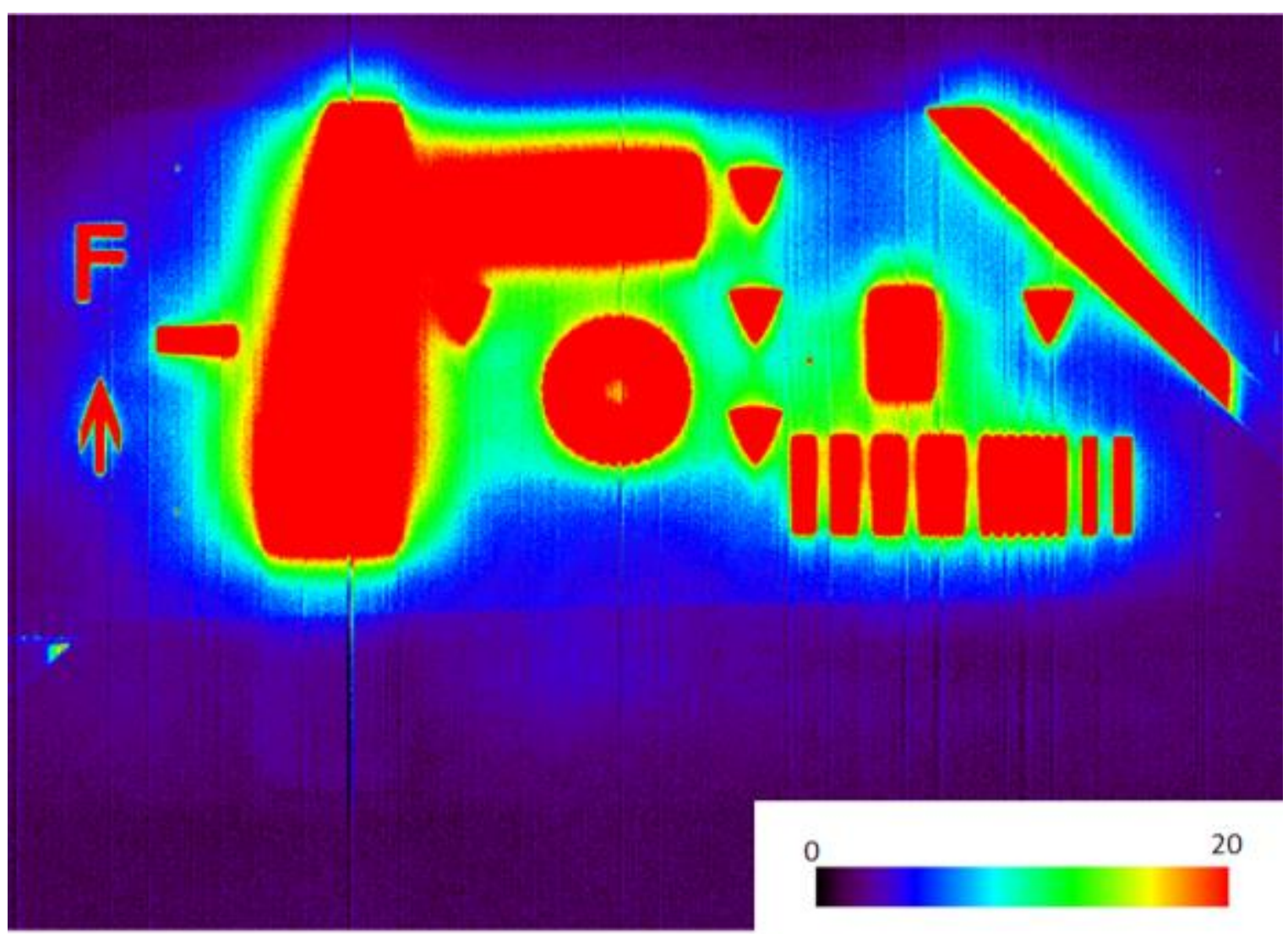




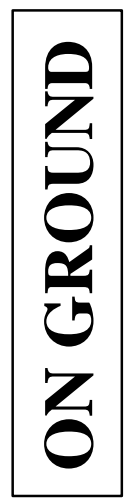

B7 image corrected from SL2, then SL1

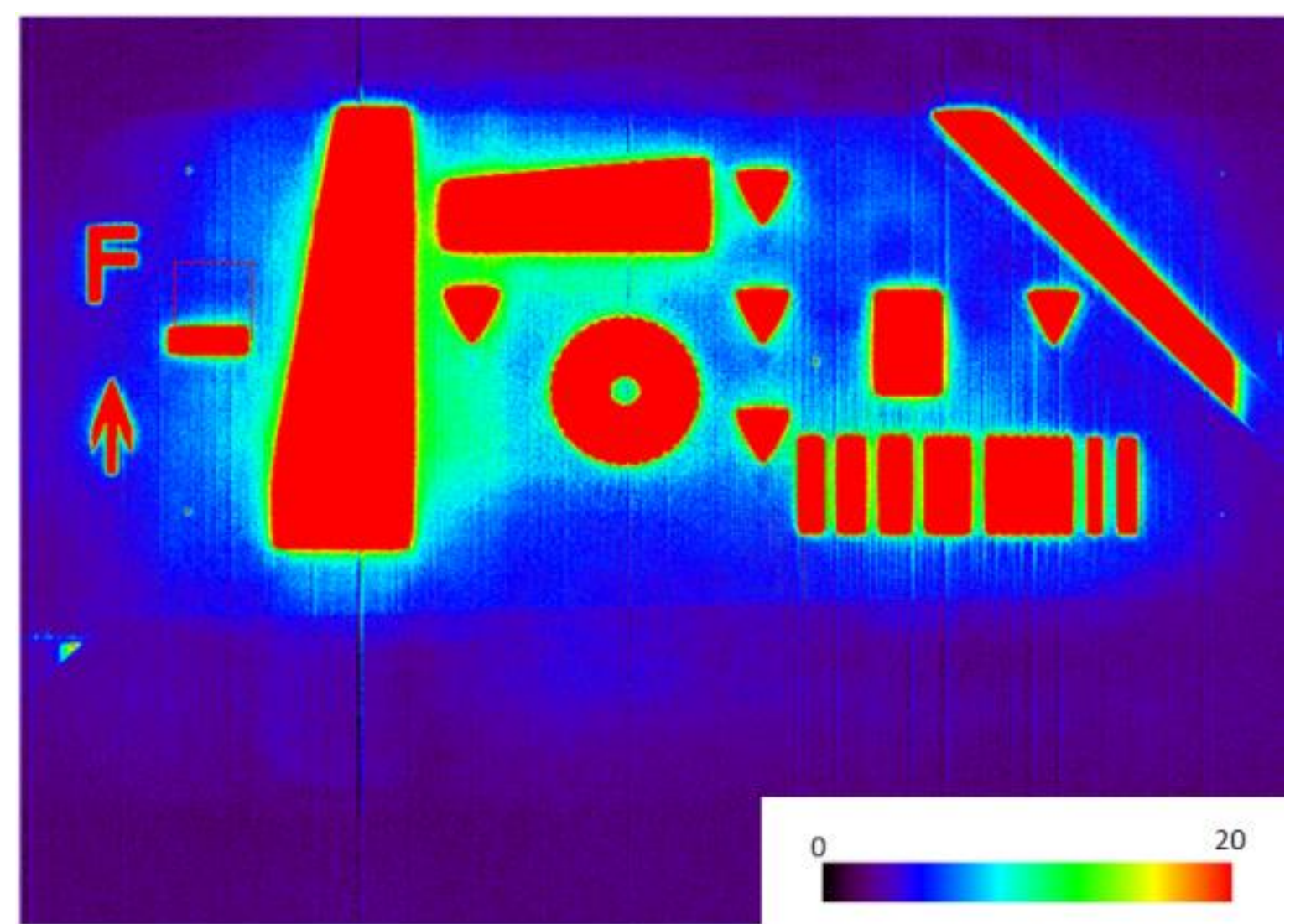


USE OF THE MOON FOR STRAY-LIGHT CORRECTION CAL/VAL

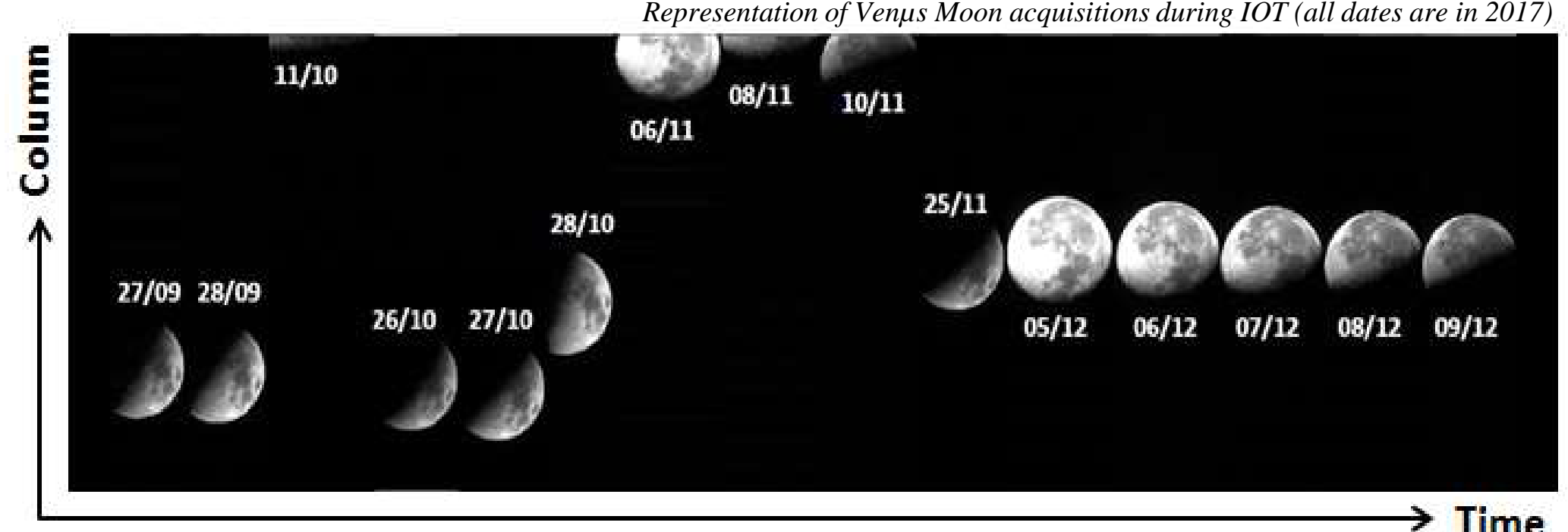

(+) quasi-uniform bright surface around edges

(+) no wavelength dependency

(+) sharp edges

(-) Moon radiance below the Lmax of the mission

$(++)$ uniform dark background

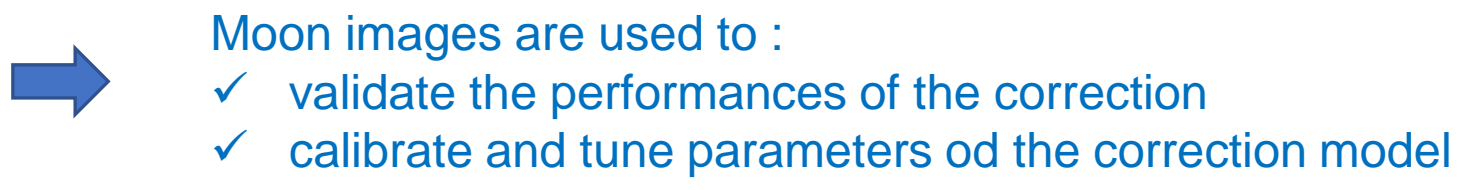


- At 10 pixels of $\mathrm{Vgt} / \mathrm{Soil}$ : additional signal in dark part shall be lower than specified SNR.

- Specified SNR is obtained at $\mathrm{N}$ pixels of the transition

$\Rightarrow$ Computation of stray-light signal reduction $(\sim 50 \%)$ at 10 pixels of the transition.
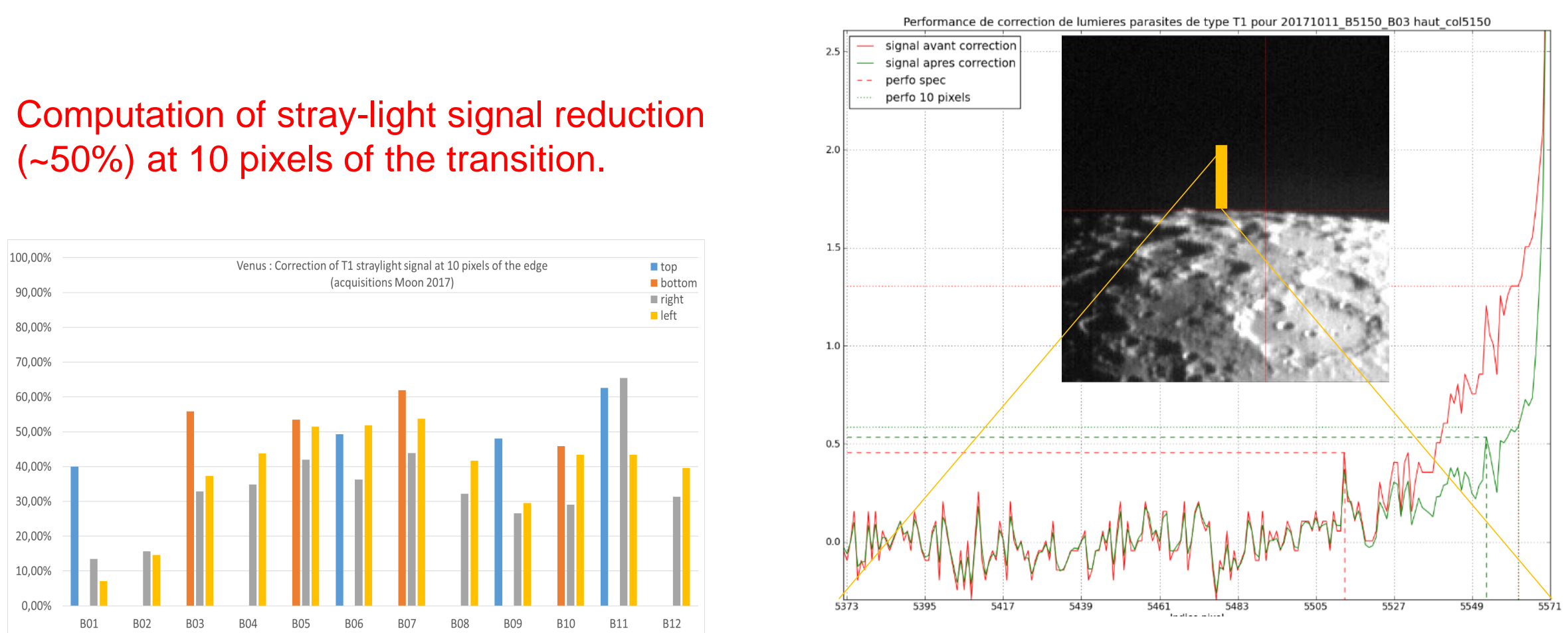


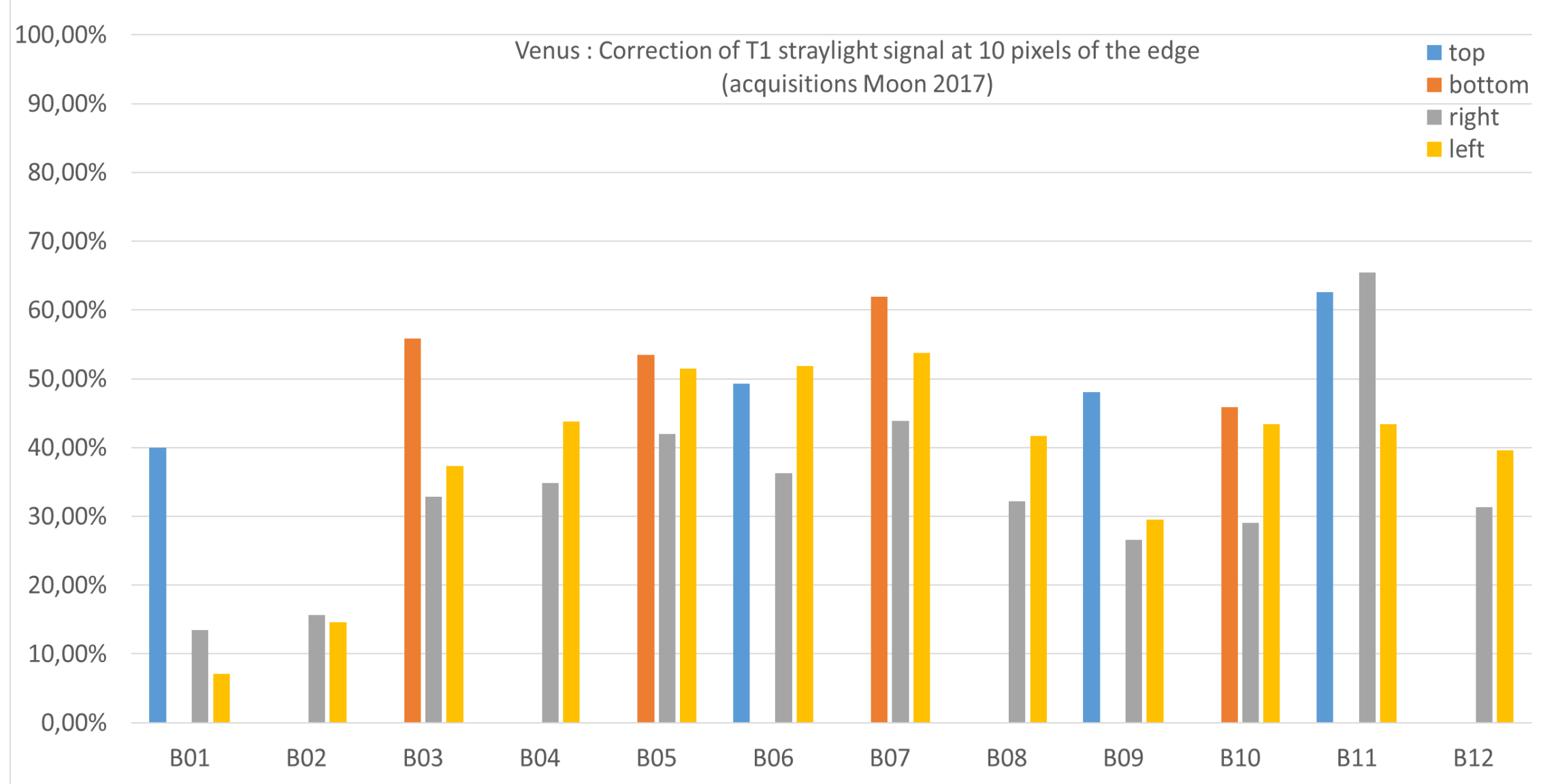




\section{STRAY-LIGHT CORRECTION PERFORMANCE (SL2)}

:_PDTIMG_LOVALD_MOONON10_20171205_B03_dark10_restoree_C2715-2735_L3500-7500_profi

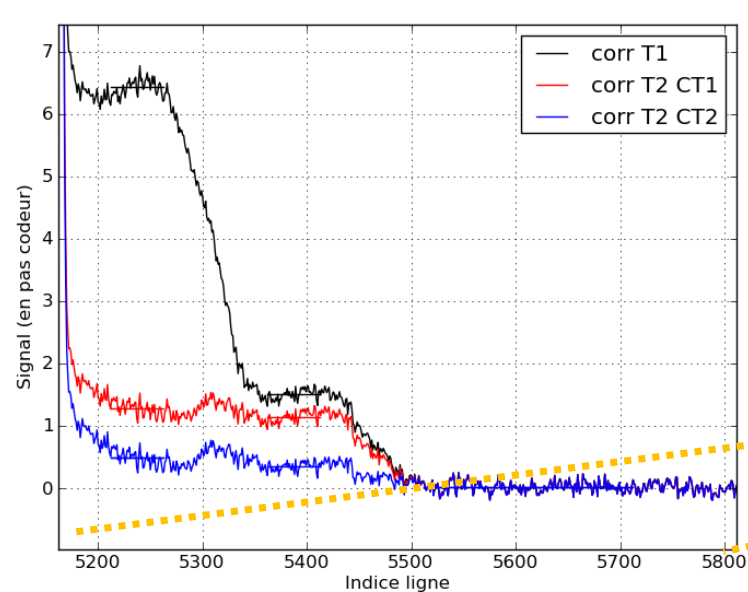

Double crosstalk on B3 : small under-correction

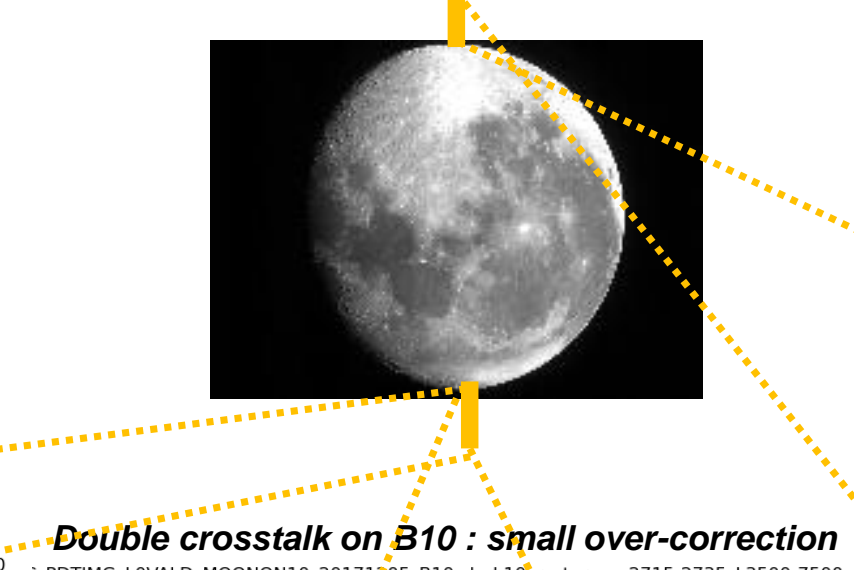

Double crosstalk on $B 10$ : small over-correction

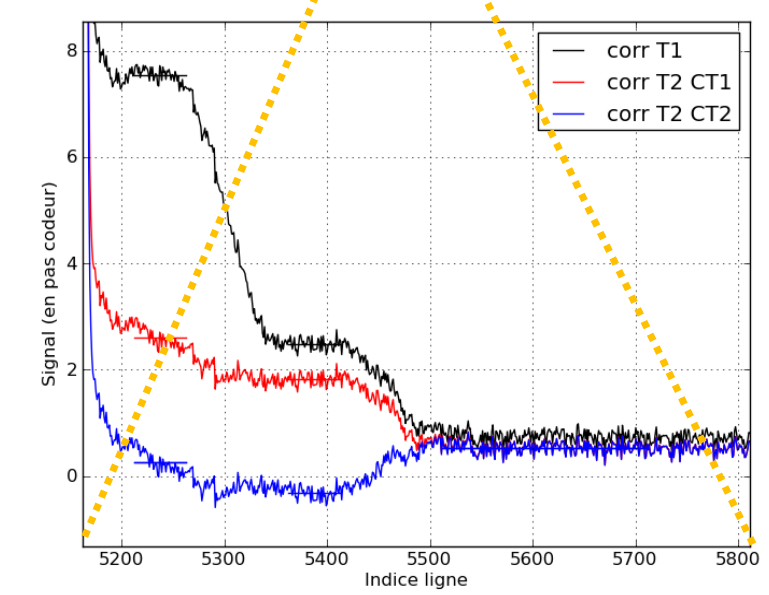

PDTIMG_LOVALD_MOONON10_20171205_B01_dark21_restoree_c2690-2710_L2000-6000_profi

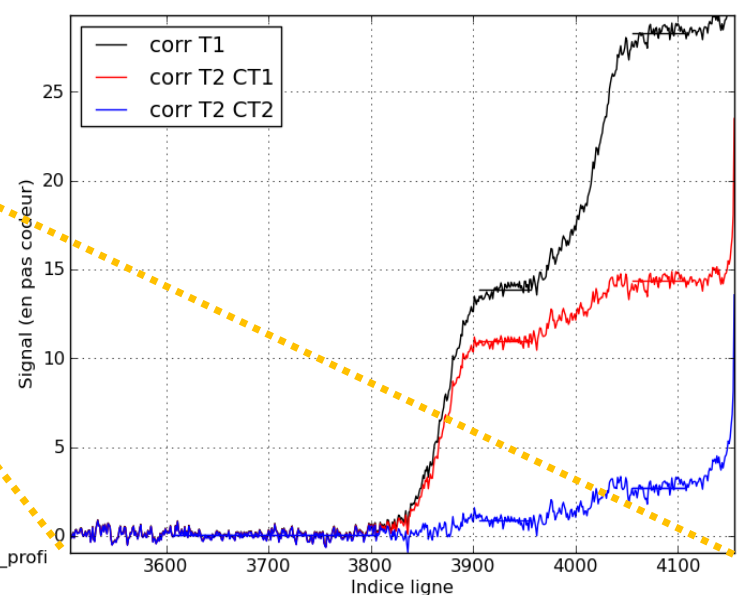

Double crosstalk on B1 : small under-correction 
STRAY-LIGHT CORRECTION PERFORMANCE (SL2)

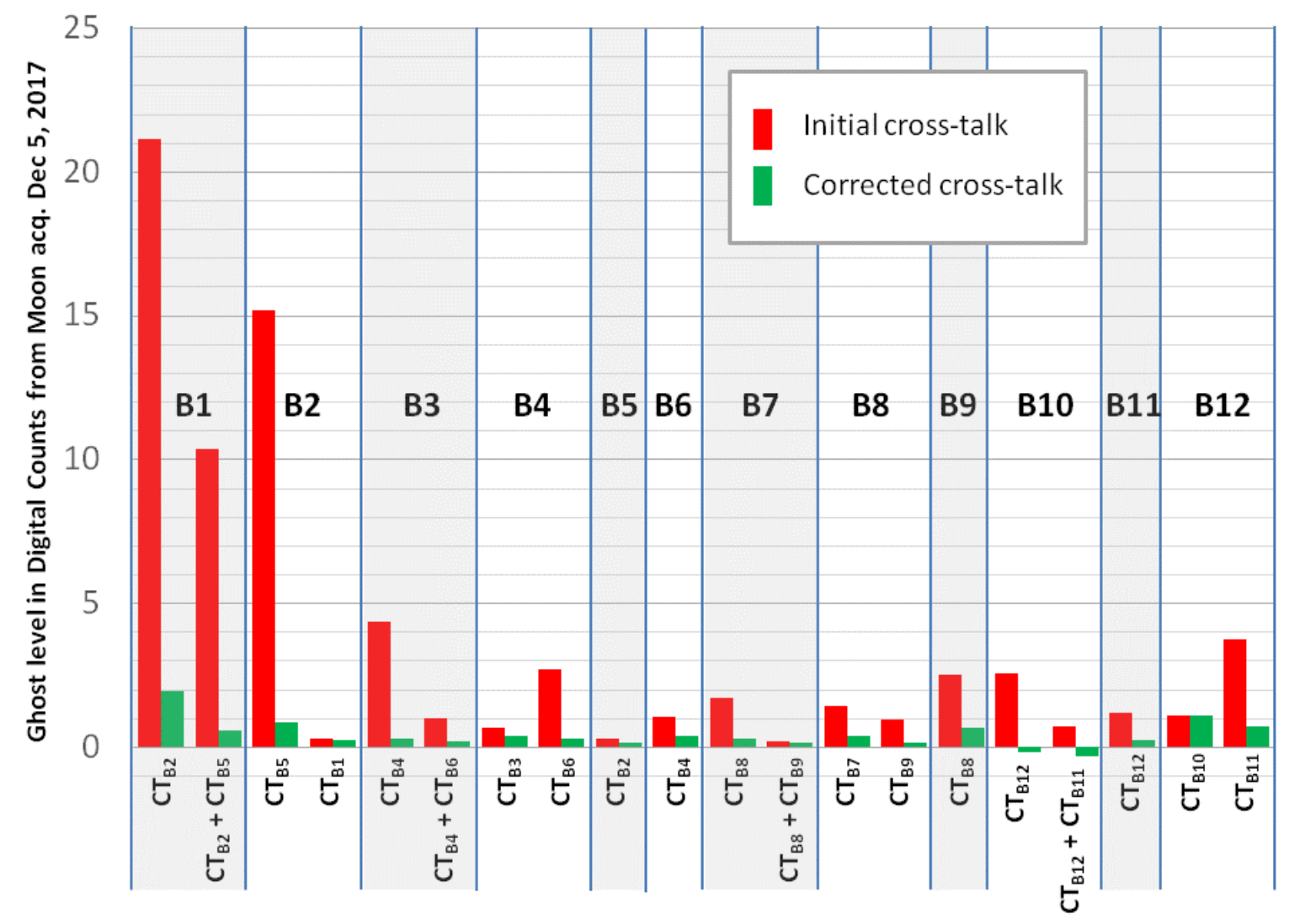

Ghost residues below 1DC (except for B1)

Good correction and linearity of the correction :

- evaluated on ground on high radiances

- Applied in-flight on Moon images (low radiances) 